\title{
Dual treatment with COX-2 inhibitor and sodium arsenite leads to induction of surface Fas Ligand expression and Fas-Ligand-mediated apoptosis in human melanoma cells
}

\author{
Vladimir N. Ivanov ${ }^{a, *}$, Tom K. Hei ${ }^{a, b}$ \\ ${ }^{a}$ Center for Radiological Research, Columbia University College of Physicians and Surgeons, New York, NY 10032, USA \\ ${ }^{b}$ Department of Environmental Health Sciences, Mailman School of Public Health, Columbia University, New York, NY 10032, USA
}

\section{A R T I C L E I N F O R M A T I O N}

Article Chronology:

Received 8 November 2005

Received version received

12 December 2005

Accepted 9 January 2006

Available online 17 February 2006

Keywords:

Fas

Fas Ligand

Apoptosis

Melanoma

Sodium arsenite

COX-2

\begin{abstract}
A B S T R A C T
Most human melanomas express Fas receptor on the cell surface, and treatment with exogenous Fas Ligand (FasL) efficiently induces apoptosis of these cells. In contrast, endogenous surface expression of FasL is suppressed in Fas-positive melanomas. We report here the use of a combination of sodium arsenite, an inhibitor of NF- $\kappa \mathrm{B}$ activation, and NS398, a cyclooxygenase-2 (COX-2) inhibitor, for restoration of the surface FasL expression. We observed a large increase of Fas-mediated apoptosis in Fas-positive melanomas. This was due to induction of FasL surface expression and increased susceptibility to Fas death signaling after arsenite and NS398 treatment. Furthermore, silencing COX-2 expression by specific RNAi also effectively increased surface FasL expression following arsenite treatment. Upregulation of the surface FasL levels was based on an increase in the efficiency of translocation to the cell surface and stabilization of FasL protein on the cell surface, rather than on acceleration of the FasL gene transcription. Data obtained demonstrate that the combination of arsenite with inhibitors of COX-2 may affect the target cancer cells via induction of FasL-mediated death signaling.
\end{abstract}

(c) 2006 Elsevier Inc. All rights reserved.

\footnotetext{
* Corresponding author. Center for Radiological Research, Columbia University, VC11-204, 630 West 168-th Street, New York, NY 10032, USA. Fax: +1 2123053229.

E-mail address: vni3@columbia.edu (V.N. Ivanov).
} 


\author{
Abbreviations: \\ Ac-IETD-CHO, N-acetyl-Ile-Glu-Thr- \\ Asp-CHO (aldehyde) \\ Ac-LEHD-CHO, N-acetyl-Leu-Glu- \\ His-Asp-CHO (aldehyde) \\ AP1, activator protein-1 \\ ATF2, activating transcription factor 2 \\ CHX, cycloheximide \\ COX-2, cyclooxygenase-2 \\ ERK, extracellular signal-regulated \\ kinase \\ GFP, green fluorescent protein \\ HO-1, heme-oxygenase-1 \\ I $\mathrm{B}$, inhibitor of NF- $\mathrm{B}$ \\ IKK, inhibitor nuclear factor kappa B \\ kinase \\ JNK, Jun N-terminal kinase \\ MAPK, mitogen-activated protein \\ kinase \\ MEK, MAPK kinase \\ MFI, medium fluorescence intensity \\ MMP, matrix metalloproteinase \\ NF-кB, nuclear factor kappa B \\ $\mathrm{PI}$, propidium iodide \\ RNAi, RNA interfering \\ TNF $\alpha$, tumor necrosis factor alpha \\ TNFR, tumor necrosis factor receptor \\ TRAF2, TNF receptor-associated \\ factor-2 \\ TRAIL, TNF-related apoptosis \\ inducing ligand
}

\section{Introduction}

Death receptors Fas (CD95/APO-1) and TRAIL Receptors-1 and-2 (DR4 and DR5) are present in a variety of tissues and play an important role in the regulation of general tissue homeostasis [1,2]. On the other hand, cancer development is often accompanied by the suppression of the surface Fas receptor expression and/or inactivation of the Fas-mediated signaling, potentially resulting in an inhibition of immunological anticancer surveillance in vivo [3]. In some highly metastatic cancer cells, including Fas-negative melanomas, Fas Ligand (FasL) surface expression is restored, providing an additional mechanism to suppress anticancer immune effector cells (so called "tumor counterattack") [4,5]. Alternatively, secretion of processed "soluble" FasL [6] or FasLbearing microvesicles [7] by cancer cells may create a specific shield, which allows them to dampen the effects of cytotoxic lymphocytes or natural killer cells. A role of endogenous FasL expression in the "tumor counterattack" hypothesis is still under active investigation [3,8,9]; however, experimental data certainly demonstrated FasL expression in some cancer cell lines, including melanomas $[6,7,10,11]$. Taken together, these observations illustrate important aspects of the general problem of the resistance of cancer cells to the induction of programmed cell death. Many recent investigations in the area of cancer therapy have been focused on the problem of overcoming resistance to programmed cell death and to restore the ability of cancer cells to undergo apoptosis [12,13]. An effective approach was the FasL gene transfer for induction of apoptosis in Fas-positive cancer cells and tumor regression in vivo [14-16].

Human melanoma, the most aggressive form of the skin cancer, is highly resistant to treatment with $\gamma$-irradiation or anticancer drugs and has altered and inhibited apoptotic signaling pathways [13,17]. Furthermore, human melanomas actively suppress the immune system [18-20]. Despite the dramatic increase in the incidence of this tumor in the past decades, the molecular mechanisms of its progression and resistance to apoptosis remain largely unknown. Melanoma cells express many different growth factors, cytokines and their receptors (including TNF $\alpha / T N F R 1$ ) for regulation of their growth and progression [19,21]. Tumor necrosis factor alpha (TNF $\alpha$ ) mediates a variety of biological functions such as cell proliferation, differentiation and cell death. TNF $\alpha$-TNFR interactions generate two different signaling cascades: the death signaling pathway (via TRADD/FADD/Caspase-8) and the survival pathway, in which the signal adapter TNFR-associated factor-2 (TRAF2) plays a primary regulatory role $[22,23]$. Upon stimulation of TNFR1 with TNF $\alpha$, TRAF2 has been implicated in the activation of transcription factors NF- $\kappa B$ and c-Jun via inhibitor nuclear factor kappa B kinase (IKK) and Jun $\mathrm{N}$ terminal kinase (JNK), respectively. The critical component 
of the NF- $\kappa \mathrm{B}$ signaling pathway is a multi-protein catalytic complex IKK that phosphorylates the NF- $\kappa B$ inhibitor, I $\mathrm{B} \alpha$ at Ser 32 and 36 [24]. Phospho- $\mathrm{I}_{\kappa} \mathrm{B} \alpha$ is then targeted for proteasome-dependent degradation, thus liberating $\mathrm{NF}-\mathrm{kB}$ p65-p50, which enters the nucleus and mediates NF-кBdependent transcription of more than 150 genes $[25,26]$. Thus, NF-кB-dependent gene expression provides a delicate balance between cell survival functions and cell death by controlling genes encoding proteins with anti-apoptotic (FLIP, c-IAP, XIAP, Bcl-xL, TRAF1, TRAF2, COX-2) and proapoptotic functions (Fas, FasL, TRAIL) $[24,27,28]$. Cyclooxygenase (COX) enzymes catalyze the synthesis of prostaglandins from arachidonic acid [29,30]. The cyclooxygenase-2 (COX-2) gene promoter contains the $\kappa \mathrm{B}$ - and $\mathrm{CRE}$ sites, and its activity is critically dependent on NF- $\kappa$ B, AP-1 and CREB/ATF2 transcription factors [31]. In normal cells, COX-2 gene is highly inducible by signals that activate the IKK $\beta-\mathrm{NF}-\kappa \mathrm{B}$ pathway. In contrast, many types of cancer cells possess high basal levels of COX-2, due to permanent activation of NF- $\kappa \mathrm{B}$ in these cells followed by expression of the COX-2 gene [29,32]. The downstream product of COX-2 enzymatic activity is prostaglandin $\mathrm{E}_{2}\left(\mathrm{PGE}_{2}\right)$, which serves as an important stimulus for induction of several cell signaling pathways, including the NF- $\mathrm{BB}$ pathway that subsequently regulates cell proliferation and motility. Indeed, inhibition of COX-2 enzymatic activity by specific pharmacological inhibitors is an effective tool for controlling both inflammation and, in some cases, cancer development [29,32].

In recent publications, we and others have proposed a number of different approaches for enhancing melanoma response to anticancer treatment. These include suppression of NF-кB activity by sodium arsenite treatment or by overexpression of the stable NF-kB inhibitor I $\mathrm{B} \Delta \mathrm{N}[33,34]$, combined treatment with sodium arsenite and EGFR inhibitors [35], selective inhibition of transcription factor ATF2 activation by the cognate peptide competitor [36,37], overexpression of transfected FasL in Fas-positive melanomas [16] and upregulation of the surface Fas receptor levels in metastatic melanomas [38]. Suppression of the NF-кBdependent expression of survival proteins and inhibition of the PI3K-AKT pathway have been linked to a dramatic increase in the sensitivity of cancer cells to endogenous TNF $\alpha$ and TRAIL $[24,39,40]$. The aim of the present study was to test whether restoration of endogenous surface expression of FasL in Fas-positive melanomas could facilitate apoptosis of these cancer cells. We found that the combined treatment of melanoma cells with sodium arsenite and NS398, an inhibitor of COX-2, would be an effective tool for induction of cancer cell apoptosis. Surprisingly, such combined treatment did not activate the FasL promoter activity and FasL transcription in melanomas but dramatically affected FasL translocation and expression on the cell surface.

\section{Methods}

\section{Materials}

Sodium arsenite and cycloheximide were obtained from Sigma (St. Louis, MO). NS398, a selective inhibitor of COX-2, was purchased from Cayman Chemical Company (Ann Arbor, Michigan). Tumor necrosis factor alpha (TNF $\alpha$ ) was purchased from Roche (Indianapolis, IN); recombinant human IL-1 $\beta$ was obtained from R\&D Systems (Minneapolis, $\mathrm{MN})$. Human soluble Fas Ligand (recombinant) was purchased from Alexis (San Diego, CA). BD Cytofix/Cytoperm kit was obtained from BD Pharmingen (San Diego, CA). Caspase inhibitors zVAD-fmk, Ac-IETD-CHO (an inhibitor of caspase-8 and caspase-6) and Ac-LEHD-CHO (an inhibitor of caspase-9) were purchased from Calbiochem (La Jolla, CA). Matrix metalloproteinase (MMP) inhibitors GM1439, MMP inhibitor II and MMP inhibitor III were obtained from Calbiochem (La Jolla, CA). Pre-cast SDS-polyacrylamide gels were purchased from BioRad (Hercules, CA).

\section{Cell lines}

Human melanoma cell lines WM35, SBcl2, LU1205 (also known as 1205lu), WM9, WM793 [18,21,41,42] and OM431 were maintained in DMEM medium supplemented with $10 \%$ fetal bovine serum, L-glutamine and antibiotics. FEMX, HHMSX and LOX, human melanoma lines [43] were maintained in RPMI1640 medium supplemented with 10\% FCS and antibiotics. Normal human melanocytes were obtained from the Department of Dermatology, Yale University (New Haven, CT) and maintained in TICVA medium for normal human melanocytes, as recommended by the manufacturer.

\section{Transfection and luciferase assay}

The NF- $\kappa \mathrm{B}$ luciferase reporter containing two $\kappa \mathrm{B}$ binding sites, Jun2-Luc reporter and vector tk-Luc [44], were used for determination of NF- $\mathrm{B}$ and $\mathrm{AP}-1$ transactivation; the FasL promoter activity was determined using reporter -453 FasLpr-Luc [45] and -1.2 kb FasLpr-Luc [46]; the Fas promoter activity was determined using -460 FASpr-Luc reporter [38]. Transient transfection of different reporter constructs $(1 \mu \mathrm{g})$ together with pCMV- $\beta$ Gal $(0.25 \mu \mathrm{g})$ into $5 \times 10^{5}$ melanoma cells was performed using Lipofectamine (Life Technologies/Invitrogen, Carlsbad, CA). Proteins were prepared for $\beta \mathrm{Gal}$ and luciferase analysis $16 \mathrm{~h}$ after transfection. Luciferase activity was determined using the luciferase assay system (Promega, Madison, WI) and was normalized based on $\beta$-galactosidase levels. In some experiments, melanoma cells were transfected with GFPFasL expression construct $[47,48]$.

\section{RNAi targeting of COX-2 mRNA}

The empty vector pSR-GFP/Neo was obtained from Oligoengine (Seattle, WA). RNAs of 19 nucleotides (ACGUUGUGAAUAACAUUCC), designed to target human COX-2 mRNA within nucleotides 354-372, were expressed using pSR-GFP/ Neo (Cox-2-RNAi) plasmid construct, which also produced a marker GFP protein. Human melanoma cells with permanent expression of COX-2 have been used for COX-2 targeting. Melanoma cells were transfected with indicated expression vectors using Lipofectamine (Life Technologies/ Invitrogen, Carlsbad, CA). 


\section{Treatment and apoptosis studies}

Cells were exposed to sodium arsenite $(1-20 \mu \mathrm{M})$ in the medium for $6-48 \mathrm{~h}$. NS398 $(50 \mu \mathrm{M})$, an inhibitor of COX-2 activity, was used with or without 5-10 $\mu \mathrm{M}$ sodium arsenite. Antibodies against TNF $\alpha$, FasL (BD Pharmingen, San Diego, CA) and TRAIL (Alexis, San Diego, CA) were added $(1-5 \mu \mathrm{g} / \mathrm{ml}) 1 \mathrm{~h}$ before sodium arsenite treatment. Apoptosis was assessed by quantifying the percentage of hypodiploid nuclei undergoing DNA fragmentation [49] or by quantifying the percentage of Annexin-V-FITC-positive cells (BD Pharmingen, San Diego, CA) or Annexin-V-PE (red fluorescence) positive cells in case of GFP-transfected (green) cells. Flow cytometric analysis was performed on a FACS Calibur flow cytometer (Becton Dickinson) using the CellQuest program.

\section{FACS analysis of Fas, FasL and COX-2 levels}

Surface and total (after cell permeabilization with BD Cytofix/Cytoperm) levels of Fas, FasL or COX-2 were determined by staining with the correspondent $\mathrm{PE}$-conjugated anti-human $\mathrm{mAb}$ (for Fas) or with primary mAb (for FasL or COX-2) and PE-conjugated goat anti-mouse secondary $\mathrm{Ab}$ and subsequent flow cytometry. Flow cytometric analysis was performed with 40,000 cells for single color staining and with 80,000 cells for double color staining using a FACS Calibur flow cytometer (Becton Dickinson, Mountain View, CA) with CellQuest program. All experiments were independently repeated 3-5 times.

\section{Western blot analysis and immunoprecipitation}

Total cell lysates (50-100 $\mu$ g protein) were resolved on $10 \%$ SDS-PAGE and processed according to standard protocols. The antibodies used for Western blotting were polyclonal anti-phospho-AKT (Ser 473), control anti-AKT (Cell Signaling, Beverly, MA), monoclonal anti- $\beta$-actin (Sigma), monoclonal anti-COX-2 from Cayman Chemical Company (Ann Arbor, Michigan), polyclonal anti-heme-oxygenase-1 (Stressgen, Victoria, BC, Canada), polyclonal anti-Bcl-xL (Santa Cruz, CA) and monoclonal anti-Fas and anti-FasL (BD Pharmingen, San Diego, CA). Optimal dilutions of primary Abs were 1:1000 to 1:10,000. The secondary Abs (anti-rabbit or anti-mouse) were conjugated to horseradish peroxidase (dilution 1:5000 to 1:10,000). Signals were detected using the ECL system (Amersham, Piscataway, NJ). Total levels of FasL were also determined using immunoprecipitation of total or membrane cell extracts with anti-FasL mAb (NOK-1) and G-protein Sepharose beads (Sigma) followed by Western blotting with anti-FasL mAb (clone G247-4) (BD Pharmingen, San Diego, CA).

\section{Electrophoretic mobility shift assay (EMSA)}

Electrophoretic mobility shift assay (EMSA) was performed for detection of NF-kB DNA-binding activity, as previously described [50] using the labeled double-strand oligonucleotide AGCTTGGGGACTTTCCAGCCG (binding sites are underlined).

\section{Results}

\section{Fas receptor and Fas Ligand expression in human melanomas}

Analysis of the surface Fas receptor levels in melanocytes and in nine lines of human melanoma cell lines (Fig. 1A) has confirmed and extended previous observations that most melanomas (both primary and metastatic) have moderate to high levels of Fas on cell surface. However, some metastatic melanomas (such as FEMX, HHMSX and OM431) exhibited significantly decreased levels of surface Fas expression due either to an inactivation of Fas gene transcription or translocation of Fas protein from the cytoplasm to the plasma membrane $[16,38,51,52]$. In contrast, LU1205, a metastatic melanoma line [18,21], possesses high surface levels of Fas (Figs. 1A, B) while simultaneously exhibiting some canonical anti-apoptotic activities, such as (phospho-Ser 473) AKT, NF-кB p65-p50 and NF-кB-dependent anti-apoptotic Bcl-xL expression (Fig. 1C). WM9 metastatic melanoma cells also have high NF- $\mathrm{B}$ p65-p50 but substantially lower phospho-AKT levels compared to LU1205 cells, while WM793 primary melanoma cells possess both very low basal NF- $k$ B p65-p50 DNA-binding activity and almost complete loss of phospho-AKT (Fig. 1C). Furthermore, all three melanoma lines demonstrated high total levels of Fas and low to modest intracellular levels of FasL (Fig. 1C). The treatment of melanoma cells with high doses (50 $\mathrm{ng} / \mathrm{ml}$ ) of soluble recombinant Fas Ligand (FasL) in the presence of cycloheximide $(2 \mu \mathrm{g} / \mathrm{ml})$ induced FasL-mediated apoptosis in most Fas-positive melanomas. However, it was evident that metastatic melanoma LU1205 was notably less sensitive to the FasL treatment, compared to the primary WM793 melanoma (in spite of similar levels of surface Fas, see Fig. 1B), likely due to more pronounced anti-apoptotic activities mediated by increased phospho-AKT, NF- $\kappa$ B p65-p50 and Bcl$\mathrm{xL}$ levels. WM9 cells demonstrated intermediate levels of FasLinduced apoptosis (Figs. 1C and D). Finally, FEMX metastatic melanoma cells with low surface Fas levels were only slightly sensitive to FasL-mediated apoptosis (data not shown).

Hence, differences in the surface Fas levels and/or susceptibility to Fas-mediated death signaling may strongly affect the apoptotic response of melanoma cells. As a result, FasL-Fas-mediated apoptosis of cancer cells could be, in principle, a powerful strategy for anticancer therapy [14,15]. Unfortunately, in vivo, a number of problems are encountered such as severe systematic liver toxicity of FasL, FasL-based fusion proteins or agonistic anti-Fas monoclonal antibodies that greatly reduce the efficacy of these reagents in anticancer treatment, despite numerous attempts to overcome this problem over the past few years $[1,53]$. As an alternative to systemic treatment with FasL, an approach based on locally restricted upregulation of the membrane form of FasL on the surface of cancer cells could be a promising tool for induction of apoptosis among cancer cells [14].

In our previous studies, we have used sodium arsenite as an inducer of cell death in a variety of cancer cells, including melanomas. Sodium arsenite treatment may stimulate apoptosis, necrosis or a combination of cell death types depending of the cell line and sodium arsenite concentration $[34,54,55]$. Unfortunately, the vast majority of melanoma cell 
A

Primary melanomas: WM35, sBcl2, WM793 Metastatic melanomas: LU1205, WM9, LOX, FEMX, HHMSX, OM431

Q Surface Intracellular

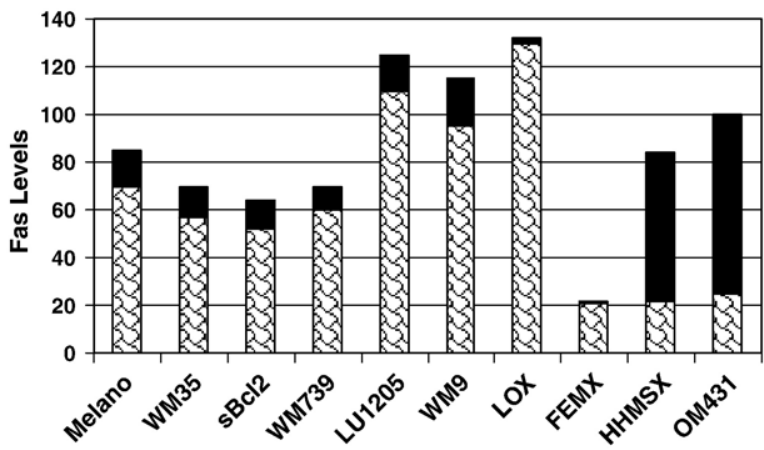

C
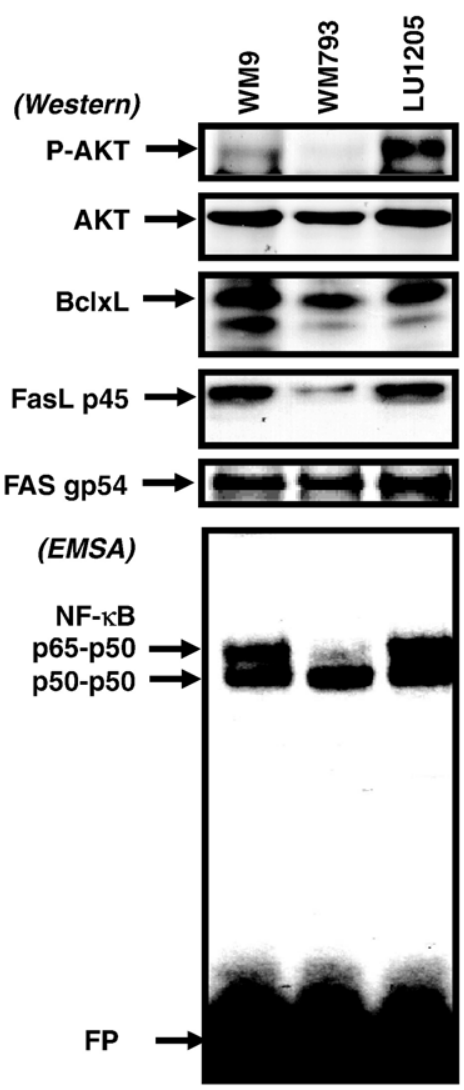

B
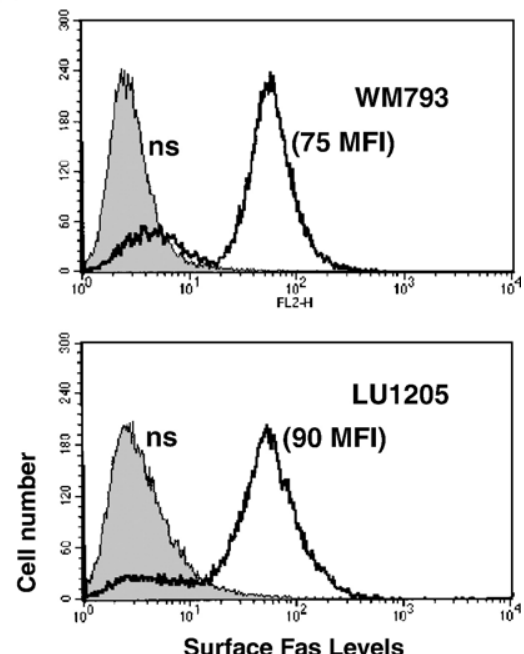

$24 \mathrm{~h}$

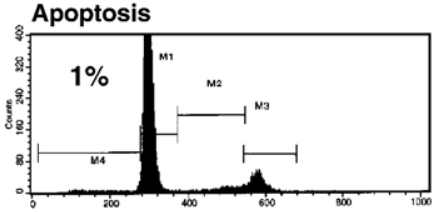

WM9

+ Fas Ligand

(50 ng/ml)

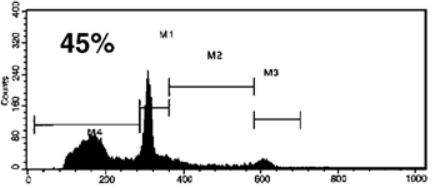

WM793, control

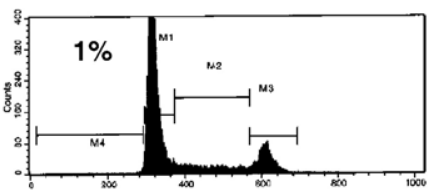

WM793

+ Fas Ligand

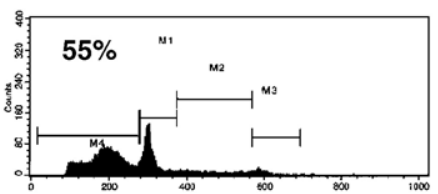

LU1205, control

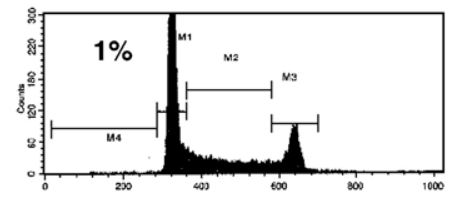

LU1205

+ Fas Ligand

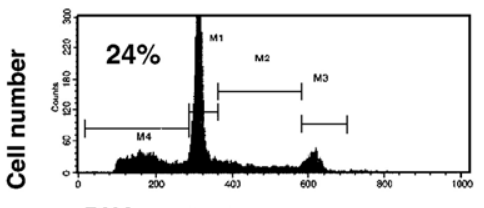

DNA content

Fig. 1 - FasL-mediated apoptosis in human melanomas. (A, B) Surface and total (after cell permeabilization) Fas levels were determined by staining with PE-conjugated anti-human Fas mAb and flow cytometry of melanocytes (Melano) and indicated human melanoma cell lines. (C) Western blot analysis of P-AKT, AKT, Bcl-xL, FasL and Fas levels in indicated melanoma cell lines. EMSA was performed for determination of NF- $\kappa$ B DNA-binding activity. Free labeled oligonucleotide probe (FP) is indicated. (D) Cell cycle-apoptosis analysis of human melanoma lines WM9, WM793 and LU1205 24 h after treatment with soluble recombinant FasL $(50 \mathrm{ng} / \mathrm{ml})$ and CHX $(2 \mu \mathrm{g} / \mathrm{ml})$. Percentages of apoptotic cells are indicated. 
lines are resistant to treatment with low doses $(2-5 \mu \mathrm{M})$ of sodium arsenite, which may induce apoptosis only in some sensitive cell lines, such as WM793 and FEMX, via TNFRmediated pathway [34]. In WM793 cells, there was a direct correlation between the dose of arsenite $(2-20 \mu \mathrm{M})$ and levels of apoptosis [34]. At the higher doses of arsenite $(>20 \mu \mathrm{M})$, pronounced secondary necrosis was also observed. Sodium arsenite is a powerful inhibitor of IKK $\beta$ and NF- $\kappa$ B activation $[34,56,57]$. We initially demonstrated the dose response inhibition of NF-кB p65-p50 DNA-binding activity and NF$\kappa \mathrm{B}$ reporter activity (Figs. $2 \mathrm{~A}$ and $\mathrm{B}$ ). It has been reported that sodium arsenite treatment strongly induced the MAPK pathways and activated ERK, p38 and JNK [58], this was followed by induction of heme-oxygenase-1 (HO-1) transcription and translation, a hallmark of oxidative stress. Consequently, we used Western blot analysis of HO-1 protein levels to confirm of the effectiveness of sodium arsenite treatment (Fig. 2A).
A
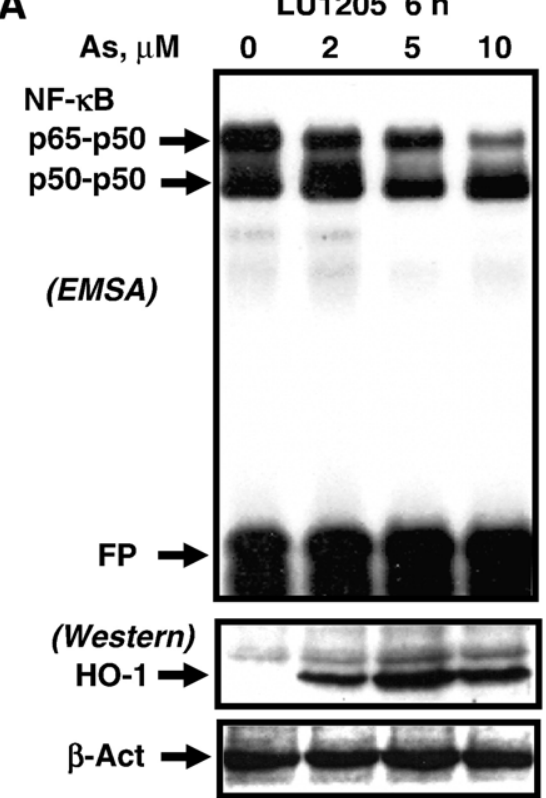

C

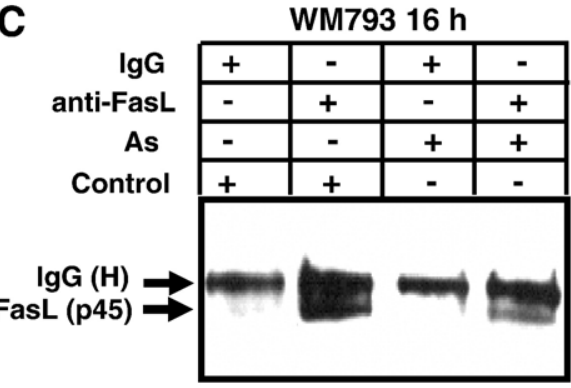

B

nF-kB-Luc घFASpr-Luc DFasLpr-Luc Etk-Luc

WM793 $6 \mathrm{~h}$

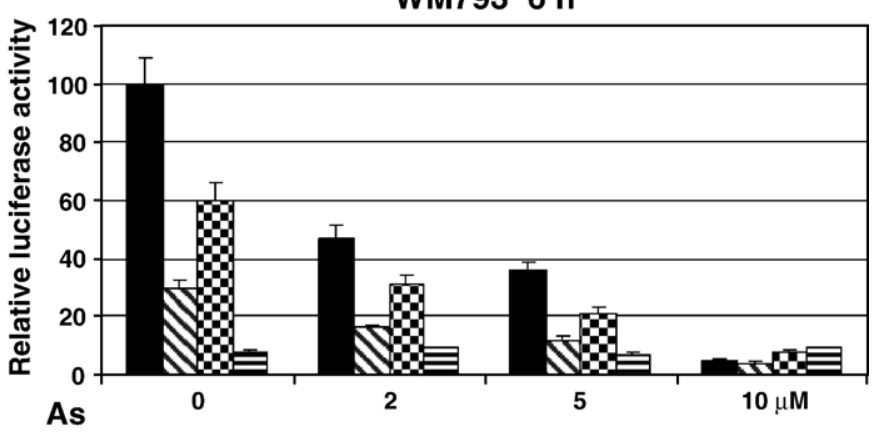

D
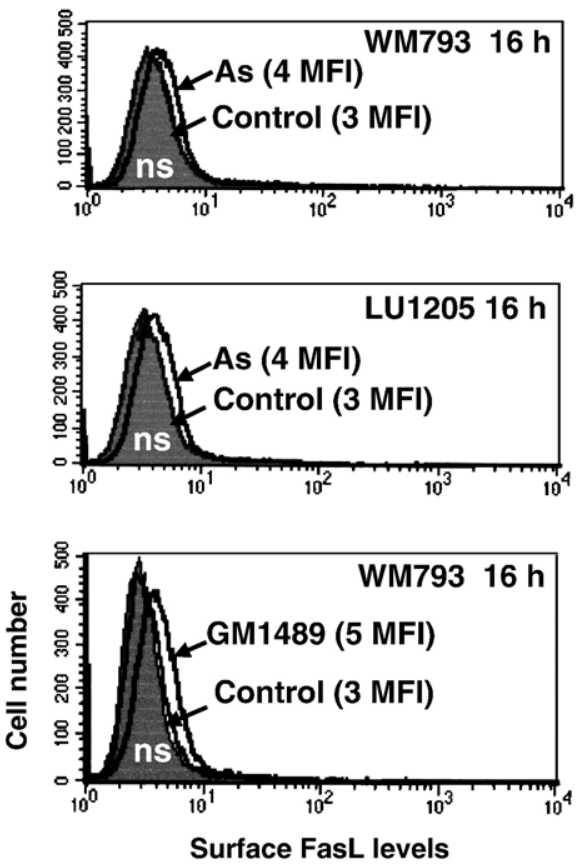

Fig. 2 - Sodium arsenite modulates NF- $\kappa$ B activity, FAS and Fas Ligand gene expression in human melanoma cells.

(A) Dose-dependent effect of sodium arsenite treatment on NF- $\kappa$ B activity. EMSA was performed for determination of NF- $\kappa$ B DNA-binding activity. Free labeled oligonucleotide probe (FP) is shown. Western blot analysis of HO-1 levels was used as a standard of efficiency of sodium arsenite treatment; $\beta$-actin was used as a protein loading control. (B) Effects of sodium arsenite on NF- $\kappa B$-dependent luciferase reporter activity and FAS- and FasL promoter activities. The reporter constructs used are: 2xNF-кB-Luc, -460 FASpr-Luc, -453 FasLpr-Luc and tk-Luc (vector with thymidine kinase promoter). Luciferase reporter activity was normalized based on $\beta \mathrm{Gal}$ activity; $\beta \mathrm{Gal}$ expression construct was cotransfected at the ratio $1 / 4$. Error bars represent mean \pm SD from three independent experiments. (C) Immunoprecipitation of total FasL protein from WM793 cell extracts with anti-FasL mAb (NOK-1) was followed by Western blot analysis with anti-FasL mAb (clone G247-4). Nonspecific mouse IgG was used as a negative control. WM794 cells were treated with sodium arsenite $(5 \mu \mathrm{M})$ for $16 \mathrm{~h}$. (D) Determination of surface FasL levels $16 \mathrm{~h}$ after treatment of indicated melanoma cells with arsenite (5 $\mu \mathrm{M})$ or with GM1489 (10 $\mu \mathrm{M})$, an MMP inhibitor, using staining with $\mathrm{mAb}$ (NOK-1), PE-conjugated goat anti-mouse secondary Ab and the flow cytometry. Control (non-treated) levels of surface FasL in melanomas were equal to nonspecific staining (ns). MFI is indicated in brackets. 
Based on these experimental data, we proposed that sodium arsenite treatment might also have regulatory effects on the endogenous Fas and FasL gene expression in melanomas via modulation of AP-1 (c-Jun/ATF2) and NF$\kappa \mathrm{B}$-dependent transcription. Since AP-1 transcription factor plays a negative role in the regulation of the Fas gene transcription [38] while NF- $\mathrm{BB}$ is the positive regulator of this gene [28], we indeed observed a strong negative response of the Fas gene promoter activity following sodium arsenite treatment (Fig. 2B). On the other hand, consequences of arsenite treatment in the regulation of the FasL transcription are quite difficult to predict because both AP-1 and NF- $\kappa$ B play positive role in this regulation among several other transcription factors, such as c-Myc, SP-1, NFAT and EGR [46,59-62]. Basal FasL promoter activity was easily detectable in WM793 cells. Furthermore, sodium arsenite, even at low doses $(1-2 \mu \mathrm{M})$, had notable negative effects on the human FasL gene promoter activity in this cell line and strongly suppressed both the basal FasL promoter and Fas promoter activities at higher concentrations (Fig. 2B).

Due to suppression of the Fas promoter activity and transcription by arsenite and continuous internalization and degradation of the surface receptor, the levels of Fas protein on the cell surface started to decrease 16-24 h after arsenite treatment (data not shown). Total levels of the membrane form of the FasL protein (p45) were determined by immunoprecipitation of WM793 cell extracts with subsequent Western blot analysis. Sodium arsenite treatment (after $16 \mathrm{~h}$ ) caused notable downregulation of total FasL protein level, probably, as a result of protein degradation (Fig. 2C). However, the membrane form of FasL could not be practically detected on the cell surface of WM793 and LU1205 melanoma cells before and after sodium arsenite treatment using immunostaining with anti-FasL $\mathrm{mAb}(\mathrm{NOK}-1)$ and the FACS analysis (Fig. 2D). Negative effects of arsenite on the FasL transcription and total FasL protein levels have been previously observed in some cell lines $[63,64]$.

Intracellular expression of FasL in WM793 and LU1205 melanoma cells and the absence of surface expression of this protein appear to indicate the existence of additional mechanisms, which prevent FasL translocation or cause rapid destabilization of FasL on the cell surface. Surprisingly, pretreatment of WM793 and LU1205 cells with several different matrix metalloproteinase inhibitors, such as $100 \mu \mathrm{M}$ phenanthroline and $10 \mu \mathrm{M}$ GM1489 (which had been previously implicated in suppression of FasL processing [65-67]), had only modest effects on the upregulation of surface FasL expression (Fig. 3D and data not shown). It indicated a relatively minor role of FasL cleavage in these lines of melanomas. Our next aim was to identify conditions for increasing the efficiency of translocation and stabilization of FasL protein on the surface of melanoma cells.

COX-2 inhibition upregulates arsenite-induced apoptosis in Fas-positive melanomas

We and others have previously demonstrated that simultaneous treatment of cancer cells with sodium arsenite in addition to specific inhibitors of cell survival pathways may dramatically increase apoptosis $[34,35,68]$. It has been established that many types of cancer cells, including melanomas [69], contain high levels of COX-2 activity. These levels can only be achieved in normal cells by stimulation with growth factors and cytokines $[29,70,71]$. Active anti-apoptotic functions of COX-2 in cancer cells have been widely reported [72-74]. Furthermore, COX-2 is one of the several important genes, which mediate breast cancer metastasis to the lung [75]. In present study, we wanted to determine whether pharmacological inhibition of COX-2 activity might increase levels of arsenite-induced apoptosis in melanoma cells.

Western blot analysis demonstrated high basal levels of COX-2 protein in several melanoma lines (Fig. 3A). Normal human lung fibroblasts, which were treated with IL-1 $\beta$ and TNF $\alpha$, served as a positive control of COX- 2 induction at the protein levels in the normal, non-cancerous, cells (Fig. 3A). Furthermore, determination of the total COX-2 levels (after cell permeabilization) by FACS analysis in several melanoma cell lines confirmed presence of high levels of COX-2 in WM9 and LOX cells and average levels in LU1205 and WM793 cells (Fig. 3B). Specific inhibition of COX-2 activity by NS398 (50 $\mu \mathrm{M})$ alone had no considerable effects on induction of apoptosis in melanoma cells. However, combined treatment with sodium arsenite $(5 \mu \mathrm{M})$ and NS398 $(50 \mu \mathrm{M})$ synergistically increased apoptosis in Fas-positive melanomas WM793, LU1205, WM9 and LOX $16 \mathrm{~h}$ and $30 \mathrm{~h}$ after treatment (Figs. 3C, D). Total levels of cell death of melanomas induced by combined treatment of sodium arsenite and NS398 were somewhat higher than apoptotic levels due to the secondary necrosis (Fig. 3C and data not shown).

To evaluate a probable role of the FasL-Fas-mediated death in arsenite and NS398-treated melanomas, we first determined levels of surface expression of Fas and FasL following such treatment. We observed a marginal effect on the surface Fas receptor levels after treatment of melanomas with arsenite and NS398. TNF $\alpha$ stimulation was used as a positive control for upregulation of Fas levels (Fig. 4A). In contrast, the surface levels of FasL were notably increased $16 \mathrm{~h}$ after combined treatment with sodium arsenite and NS398 in WM9, LU1205 (Fig. 4B), WM793 and LOX melanoma cells (data not shown). Arsenite or NS398 alone did not induce a notable expression of FasL on the cell surface (Fig. 4B). Anti-FasL inhibitory mAb (NOK-1) partially suppressed apoptosis induced with arsenite and NS398 in all melanoma lines tested, while effect of anti-TNF $\alpha$ mAb was pronounced only in WM793 cells (Fig. 4C). This effect of anti-TNF mAb on WM793 cells was likely due to inhibition of arsenite-induced TNF $\alpha$-mediated apoptosis in these cells [34]. To demonstrate a dependence of apoptosis induced by arsenite and NS398 on caspase activities, we used specific inhibitors of caspases. Both Ac-IETD-CHO (an inhibitor of caspase-8 and caspase-6) and Ac-LEHD-CHO (an inhibitor of caspase-9) partially suppressed arsenite and NS398-induced apoptosis, although Ac-IETD-CHO was more effective (Fig. 4D), indicating that death-receptor/caspase-8-mediated cascade operated during apoptosis. A general caspase inhibitor, zVAD-fmk $(5 \mu \mathrm{M})$, was quite efficient for suppression of apoptosis, although this suppression was not complete, likely due to secondary necrosis (Fig. 4D). 


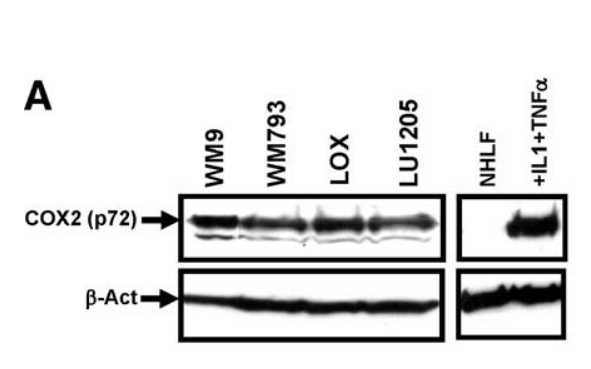

\section{C}

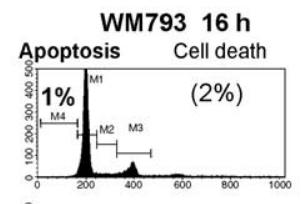

B
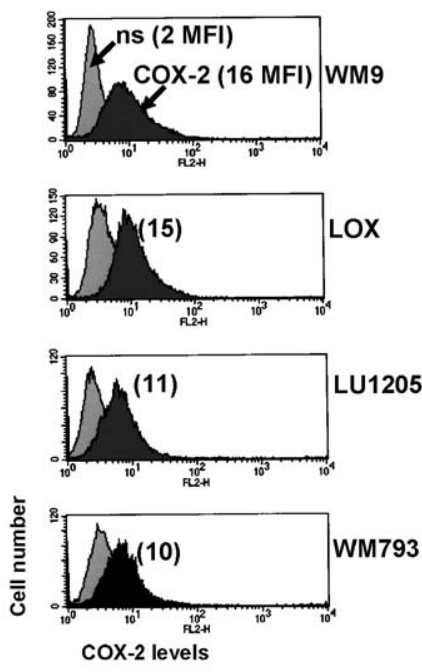
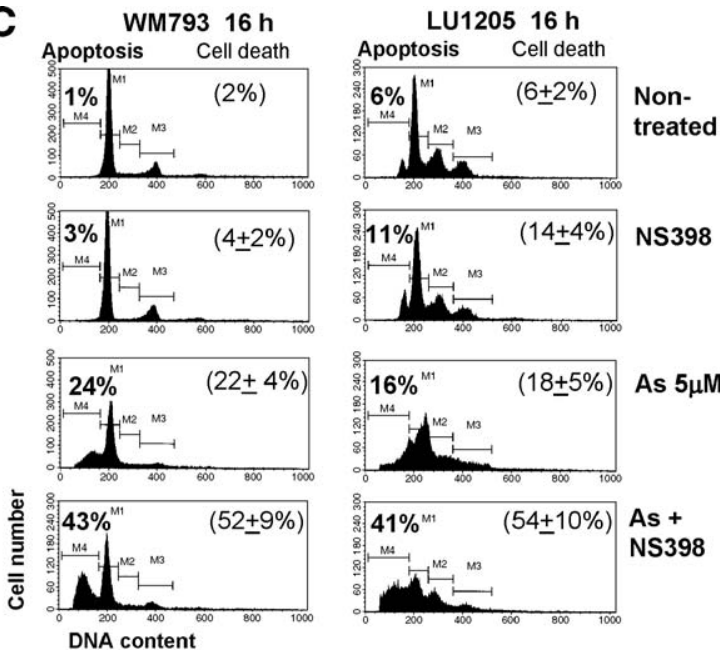

D

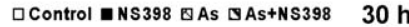

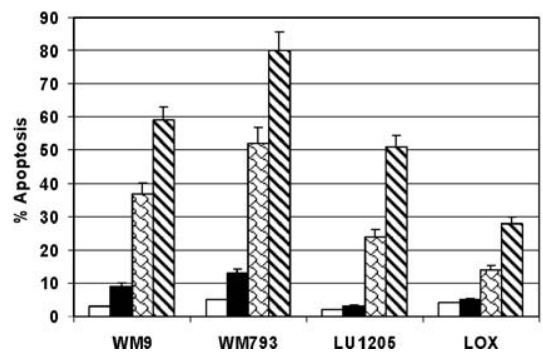

Fig. 3 - COX-2 expression in human melanomas. (A) Western blot analysis of COX-2 levels in the indicated cell lines. $\beta$-actin was used as a loading control. Normal human lung fibroblasts were untreated or treated with IL-1 $(2 \mathrm{ng} / \mathrm{ml})$ and TNF $\alpha(10 \mathrm{ng} / \mathrm{ml})$ for $4 \mathrm{~h}$. (B) Total COX-2 levels in human melanomas have been determined by FACS analysis after cell permeabilization and staining using mAb against COX-2, PE-conjugated goat anti-mouse secondary $\mathrm{Ab}$ and the flow cytometry. Nonspecific (ns) staining; medium fluorescence intensity (MFI) is indicated in brackets. (C, D) Inhibition of COX-2 activity by NS398 (50 $\mu$ M) had synergistic effects on arsenite-induced apoptosis in COX-2-positive human melanomas. Levels of apoptosis have been determined by FACS analysis of PI-stained melanoma cells $16 \mathrm{~h}$ (C) and $30 \mathrm{~h}$ (D) after treatment with sodium arsenite $(5 \mu \mathrm{M})$, NS398 $(50 \mu \mathrm{M})$ or their combination; levels of total cell death have been determined by Trypan blue staining. Error bars represent mean $\pm \mathrm{SD}$ from three independent experiments.

Taken together, these data demonstrated that the upregulation of the surface FasL expression in several melanoma lines following the combined treatment with arsenite and COX-2 inhibitor could potentially explain an increase in the apoptotic response. Hence, in addition to basal apoptosis driven by sodium arsenite (which was TNF $\alpha$-mediated in WM793 cells), combined treatment with sodium arsenite and NS398 induced FasL-Fas-mediated apoptosis in melanoma cells.

Regulation of the FasL expression by combined treatment with sodium arsenite and NS398

There are several possible targets for modulation of FasL expression on the cell surface: (i) the FasL promoter activity and subsequent transcription and translation; (ii) posttranslational modifications of FasL; (iii) FasL protein translocation from the cytoplasmic pool through secretory lysosomes $[47,48]$ to the cell surface; (iv) membrane FasL internalization and degradation; (v) membrane FasL cleavage on the cell surface by matrix metalloproteinases (that resulted in secretion of the soluble FasL). In addition, tumor cell secretion of FasL-bearing microvesicles has been described [7]. Interestingly, FasL promoter activity and transcription were partially suppressed by sodium arsenite treatment (Fig. 2B). Furthermore, the COX-2 inhibitor NS398 alone, or in the combination with sodium arsenite, was also an effective suppressor of the NF- $\mathrm{B}$ transactivation and the FasL promoter activity and transcription in melanomas (Fig. 5A). Negative regulation of NF- $\mathrm{B}$ activity by COX-2 inhibitors has been well documented [72]. Experimental results obtained indicate that posttranslational regulation of the FasL, rather than regulation of the FasL gene transcription, might be responsible for increased surface expression of FasL 10-16 h after treatment with sodium arsenite and NS398 (Figs. 4B, 5B). This FasL translocation from the cytoplasm to cell surface is an active process that is generally dependent on new protein synthesis including synthesis of some helper proteins. The presence of cycloheximide (CHX) $(1-5 \mu \mathrm{g} / \mathrm{ml})$, an inhibitor of translation, indeed suppressed positive effects of combined treatment of arsenite and NS398 on the surface FasL levels (Fig. 5B), thereby linking regulation of the surface 
A
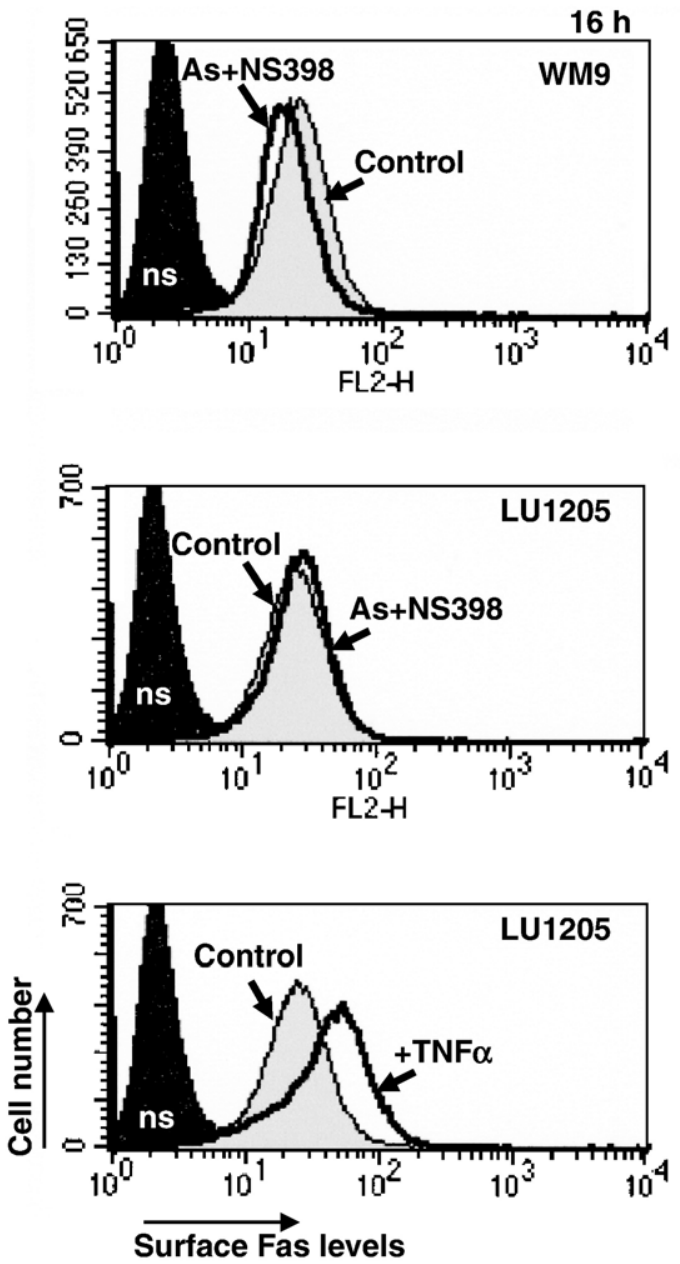

C

$24 \mathrm{~h}$

$\square$ Control $\mathbf{A s}+\mathrm{NS}+\mathrm{aTNF} \square$ As+NS+lgG As+NS+aFasL

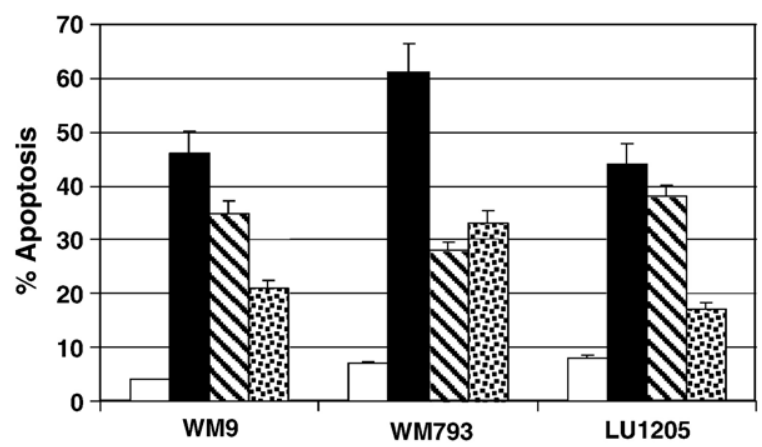

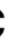

B
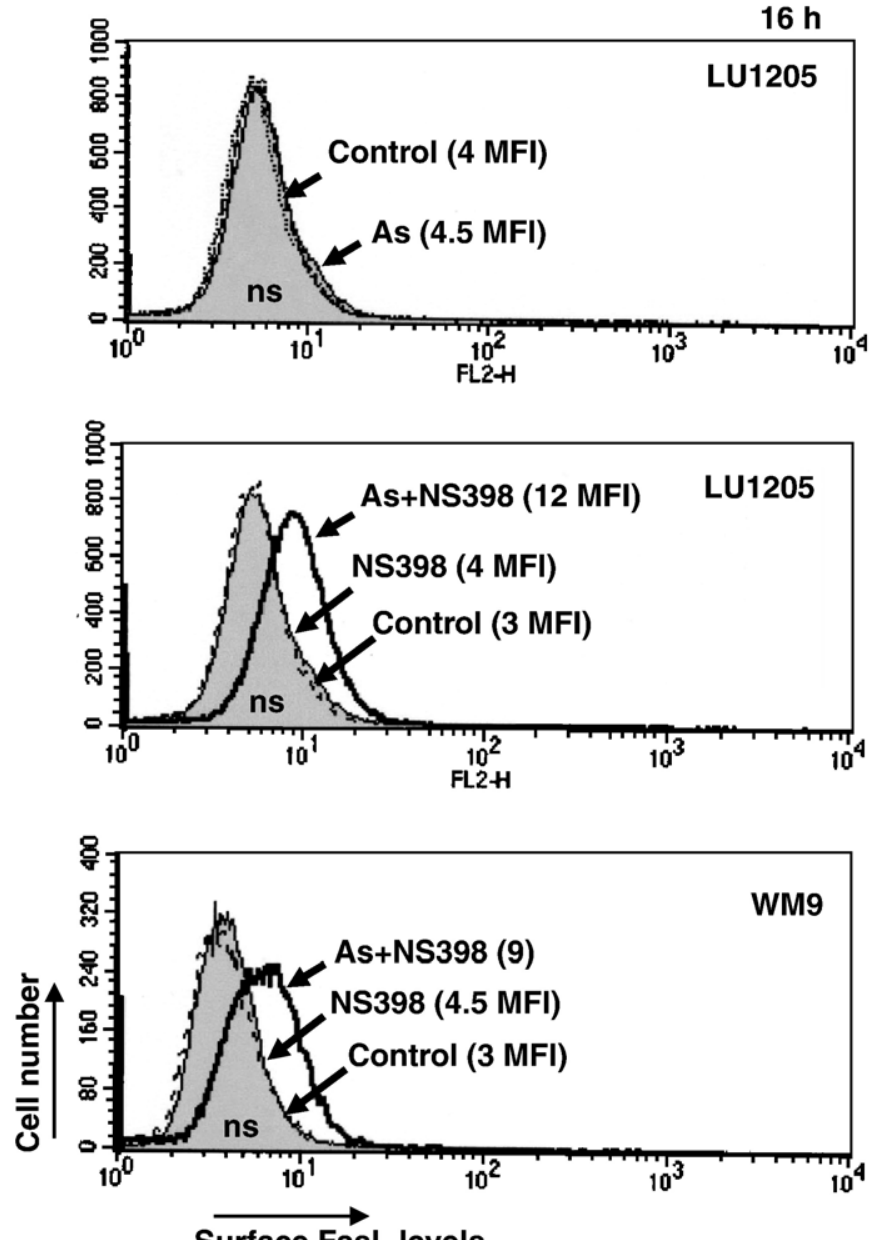

D

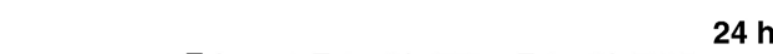

$24 \mathrm{~h}$

Control 0 As+NS+IETD $\mathbb{A}$ As+NS+ZVAD - As+NS 目 As+NS+LEHD

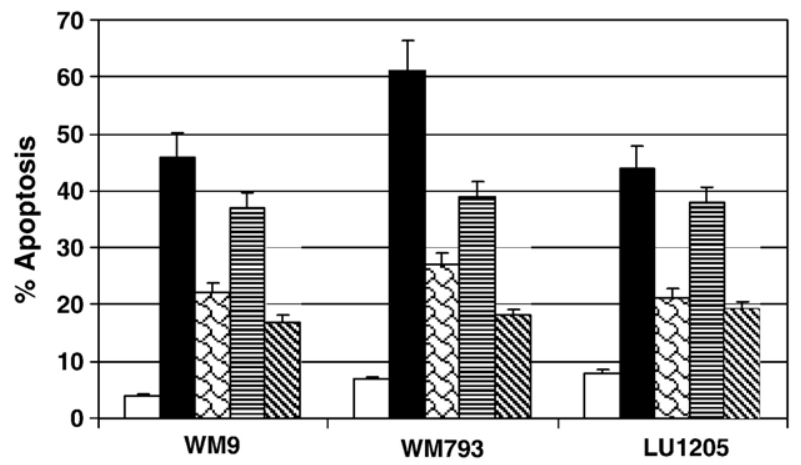

Fig. 4 - Upregulation of the surface FasL levels after treatment of melanoma cells with a combination of NS398 and sodium arsenite. (A) Surface Fas levels after treatment of indicated melanomas with sodium arsenite (5 $\mu \mathrm{M})$ and NS398 (50 $\mu \mathrm{M})$. TNF $\alpha(10$ $\mathrm{ng} / \mathrm{ml}$ ) was used as a positive regulator of Fas expression. Control non-treated cells (Control) and nonspecific (ns) staining cells with IgG-PE are indicated. (B) Surface FasL levels were determined using anti-FasL $\mathrm{mAb}$ (NOK-1) and PE-conjugated goat anti-mouse secondary $\mathrm{Ab}$ in flow cytometry. Control (non-treated) levels of FasL were the same as nonspecific (ns) staining. Only combined treatment with As $(5 \mu \mathrm{M})$ and NS398 $(50 \mu \mathrm{M})$ induced specific and pronounced changes in the surface FasL levels of melanoma cells. (C) Pretreatment of the cell cultures with anti-FasL inhibitory $\mathrm{mAb}$ (NOK-1) $(2 \mu \mathrm{g} / \mathrm{ml})$ or with anti-TNF $\alpha \mathrm{mAb}$ partially suppressed apoptosis in the indicated melanoma cell lines, which was induced by dual treatment of sodium arsenite and NS398. (D) Effects of caspase inhibitors (10 $\mu \mathrm{M})$ on apoptosis in melanoma cells, induced by sodium arsenite and NS398. 
A

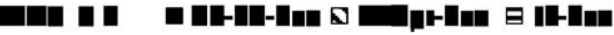

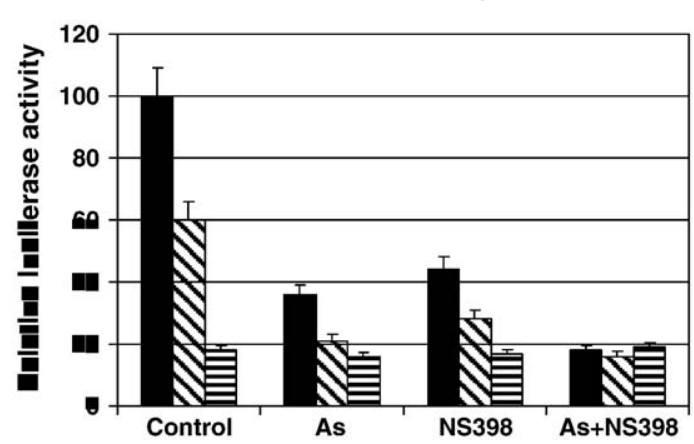

B
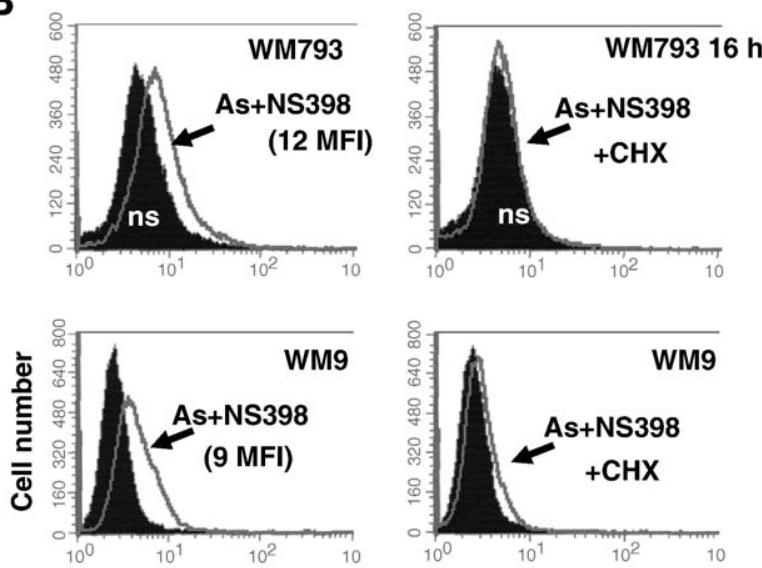

FasL levels

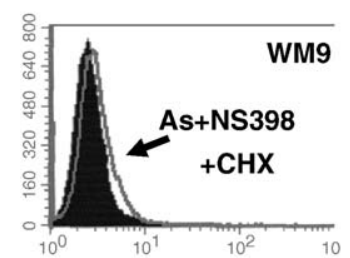

FasL levels

C

WM9 $12 \mathrm{~h}$

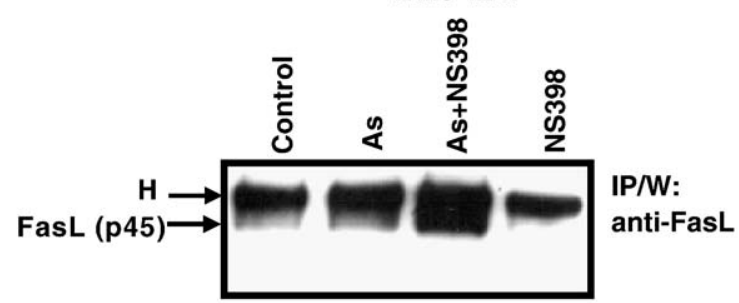

D

WM9

GFP-FasL

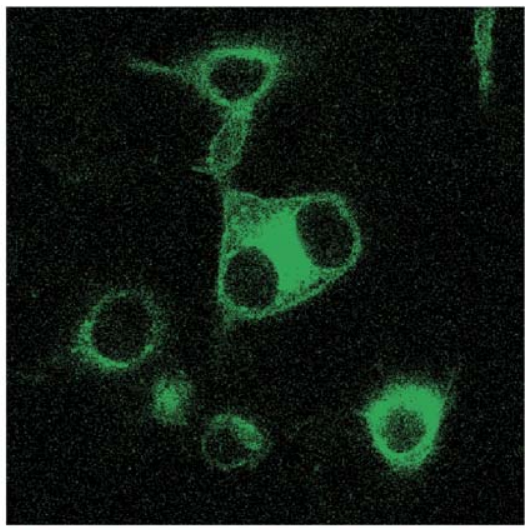

Anti-FasL-TR

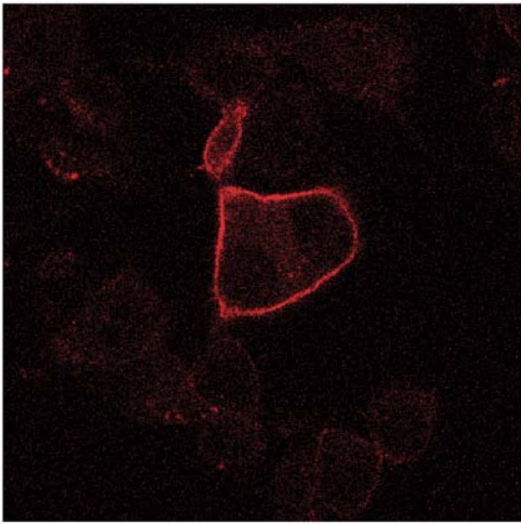

Merged

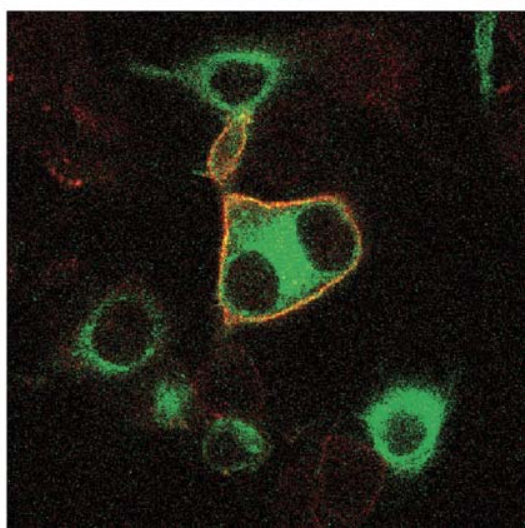

Fig. 5 - Expression of endogenous and transfected FasL on the cell surface of melanomas. (A) Effects of combined treatment with sodium arsenite and NS398 on the FasL promoter activity; -1.3 kb FasLpr-Luc and 2xNF- $\kappa$ B-Luc constructs were used for luciferase assay. (B) Effects of cycloheximide (CHX) $(2 \mu \mathrm{g} / \mathrm{ml})$ on surface FasL levels induced by arsenite and NS398 in WM793 and WM9 melanoma cells. (C) Protein levels of FasL in WM9 cells after indicated treatment were determined using immunoprecipitation with mAb against human FasL (NOK-1) and Western blot analysis with anti-FasL mAb (clone 247-4). Position of membrane FasL (p45) is indicated. $\mathrm{H}$ is heavy chains of mouse IgG. (D) WM9 cells were transfected with GFP-FasL expression construct. Sixteen hours after transfection, cells were treated with arsenite (As), NS398 or combination of As and NS398. Confocal analysis of FasL-GFP translocation to the cell surface of WM9 melanoma was performed 30 min after treatment with arsenite $(5 \mu \mathrm{M})$ and NS398 $(50 \mu \mathrm{M})$. Surface expression of FasL was detected using mAb (NOK-1) against the surface epitope of FasL and the secondary anti-mouse Ab labeled with Texas Red.

FasL expressions with genes controlling intracellular trafficking.

As it was previously mentioned (Fig. 2D), inhibition of matrix metalloproteinase (MMP) activities, which were involved in cleavage of the membrane form of FasL $[65,67,76]$, had only modest positive effects on the surface levels of FasL in human melanoma lines indicating that the membrane FasL cleavage was not well pronounced in these cancer cells. Immunoprecipitation of total cell extracts by anti-FasL mAb and Western blot analysis demonstrated an upregulation of the total FasL protein level $12 \mathrm{~h}$ after combined treatment of WM9 cells with arsenite and NS398 likely due to an increased stability of FasL protein on cell surface (Fig. 5C). 
Acceleration of GFP-FasL translocation from the cytoplasmic pool to the cell surface by combined treatment of melanoma cells with sodium arsenite and COX-2 inhibitor

To evaluate the effects of NS398 and sodium arsenite on the translocation of FasL to the cell surface, we transfected WM9 cells with GFP-tagged FasL (GFP-FasL) expression construct (Fig. 5D). Sixteen hours after transfection, $23 \% \pm 7 \%$ of GFPFasL-transfected (green) cells expressed FasL on their surface (determined by staining with NOK-1 mAb and FACS analysis). According to results described previously $[47,48]$, an induced GFP-FasL translocation from the cytoplasm to the cell surface was a relatively rapid process. Indeed, $30 \mathrm{~min}$ after treatment of GFP-FasL-transfected cells with sodium arsenite or especially after combined treatment with arsenite and NS398, the surface expression of FasL (determined with NOK-1 mAb and FACS analysis) substantially increased: from $29 \%$ to $57 \%$ positive cells. NS398 alone was not really effective. This initial increase in FasL surface expression was followed by a significant decline of this level 2-6 $\mathrm{h}$ after treatment (Fig. 6 and data not shown). Confocal microscopy with anti-FasL mAb (NOK-1, against the extracellular domain of human FasL) also demonstrated surface expression of GFP-FasL in some treated cells (Fig. 5D). These observations provide a direct proof of the role of arsenite and NS398 in the upregulation of the FasL translocation to the cell surface. Thus, combined treatment of melanoma cells with NS398 and arsenite increased and stabilized protein levels of FasL in the cells and synergistically increased FasL translocation from the cytoplasmic pools to cell surface.

\section{COX-2 downregulation by specific RNAi}

As an alternative approach for suppression of COX-2, silencing COX-2 expression with COX-2 RNAi has been used. We designed and created COX-2 RNAi expression
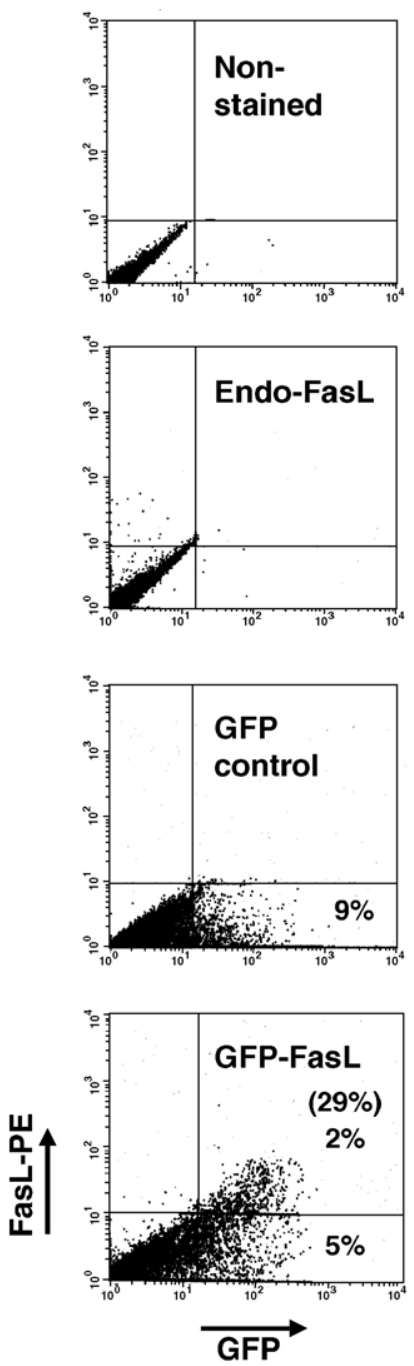

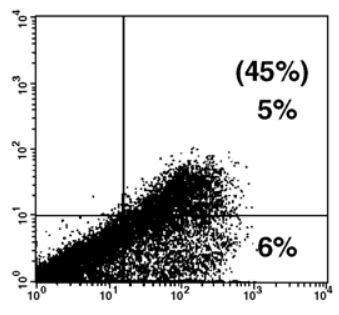

GFP-FasL + As, $0.5 \mathrm{~h}$

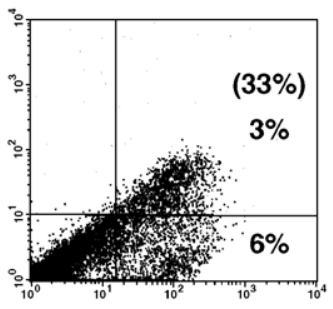

GFP-FasL + NS398, $0.5 \mathrm{~h}$
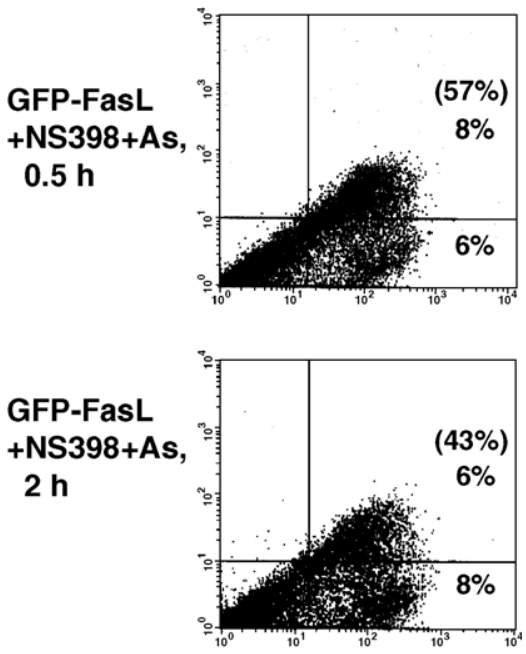

Fig. 6 - GFP-FasL translocation to the cell surface. WM9 melanoma cells were transfected with FasL-GFP construct. Sixteen hours after transfection, cells were not treated or treated with arsenite $(5 \mu \mathrm{M})$ and NS398 (50 $\mu \mathrm{M})$ for the next 0.5-2 h. Then, cells were stained with anti-FasL $\mathrm{mAb}$ (NOK-1), which recognizes the surface epitope of FasL, and with the secondary $\mathrm{PE}$-conjugated goat anti-mouse $\mathrm{Ab}$ and analyzed by flow cytometry. A normalized ratio of the surface FasL-positive cells to the total number of GFP-positive transfected cells is indicated in brackets. 
construct based on pSR-GFP/Neo vector from Oligoengine (Seattle, WA). Following transfection by COX-2 RNAi or the empty vector and subsequent selection in the presence of G418, two mass cultures of WM793 melanoma enriched with COX-2 RNAi/GFP or vector/GFP were established. In both types of transfected cells, GFP was localized in the cytoplasm and in the nucleus (Fig. 7A). Determination of COX-2 protein levels by Western or FACS analysis demonstrated a downregulation of basal COX-2 protein levels by COX-2 RNAi expression in WM793 cells (Figs. 7B and C). Interestingly, this was accompanied by upregulation of the surface FasL levels in transfected cells after arsenite treatment (Fig. 7D). The percentage of Annexin-V-PE positive (red) apoptotic cells substantially increased after treatment of WM793/COX-2RNAi (green) cells by sodium arsenite (Fig. 7E). A combination of arsenite and NS398 increased levels of apoptosis in control cells, which were transfected with the empty pSR-GFP/Neo vector. Taken together, these data demonstrated relatively similar effects on the FasL surface expression and arseniteinduced apoptosis either after pharmacological inhibition of
A

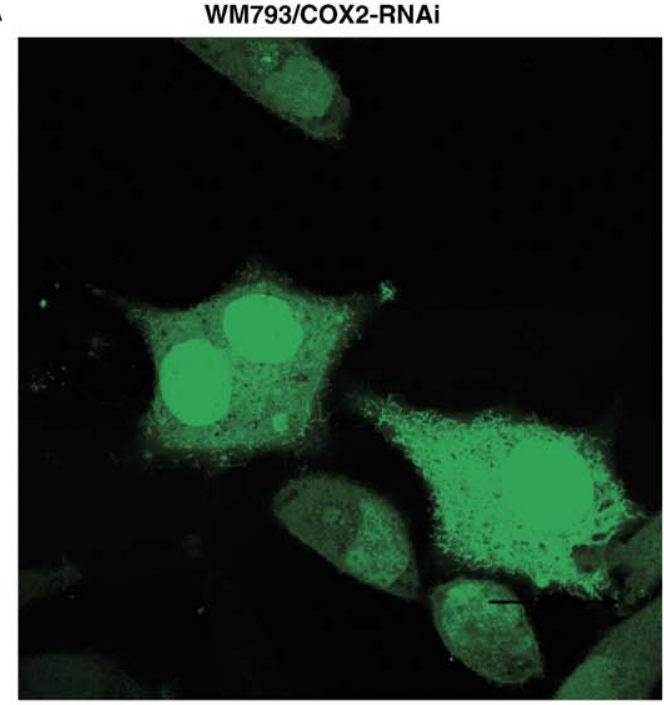

D
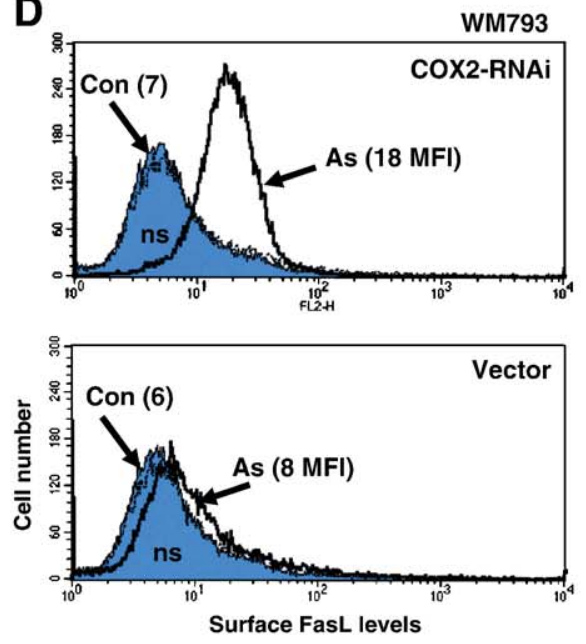

E

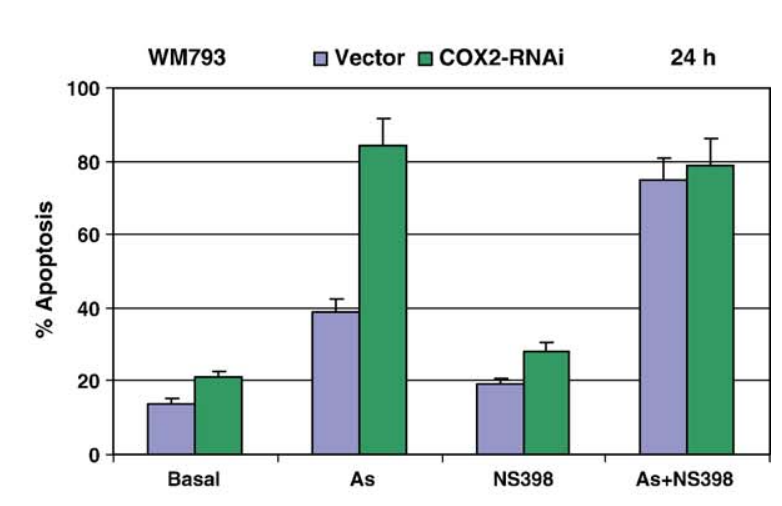

B

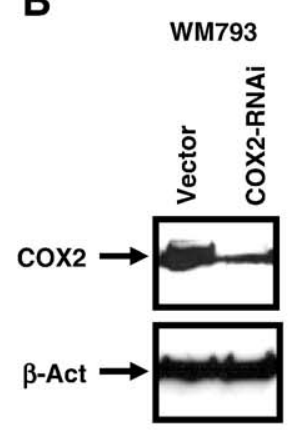

C
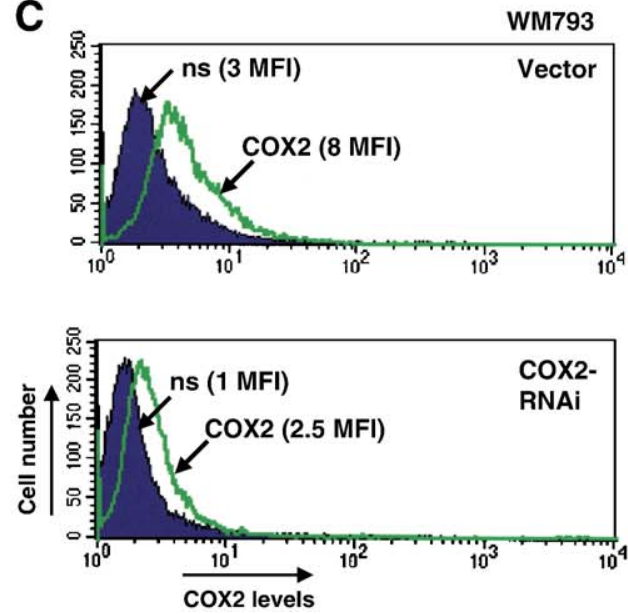

Fig. 7 - Downregulation of COX-2 protein levels by targeting of COX-2 mRNA with specific RNAi of 19 nucleotides leads to upregulation of FasL expression and acceleration of arsenite-induced apoptosis in human melanoma WM793. (A) RNAi, designed to target human COX-2 mRNA within nucleotides 354-372, was expressed using pSR-GFP/Neo (Cox-2-RNAi) vector, which also produced a marker GFP protein. Human melanoma WM793 cell line with moderate basal expression of COX-2 has been used for COX-2 silencing. Two mass cultures of WM793 cells were obtained after transfection with the empty vector or with the COX-2 RNAi expression construct and subsequently selected in the presence of G-418 (400 $\mu$ g/ml). GFP expression is localized in the cytoplasm and in the nucleus of transfected cells. (B) Total protein levels of COX-2 expression in selected cultures were detected by Western analysis. (C) FACS analysis of transfected and selected cells using monoclonal anti-COX-2 antibody and the secondary anti-mouse Ab labeled with PE confirmed a downregulation of COX-2 levels in WM793/COX-2 RNAi cells from 8 MFI to 2 MFI. (D) Sodium arsenite (As, $5 \mu \mathrm{M}$ ) treatment of control (Vector) and COX-2 knockdown cells dramatically increased surface expression of FasL. FACS analysis was performed as indicated in the legend to Fig. 4. (E) Percentage of Annexin-V-PE-positive (red) apoptotic cells among transfected GFP-positive cells was determined using FACS analysis. Treatment of WM793 cells with arsenite, NS398 or their combination was performed for $12 \mathrm{~h}$. 
A

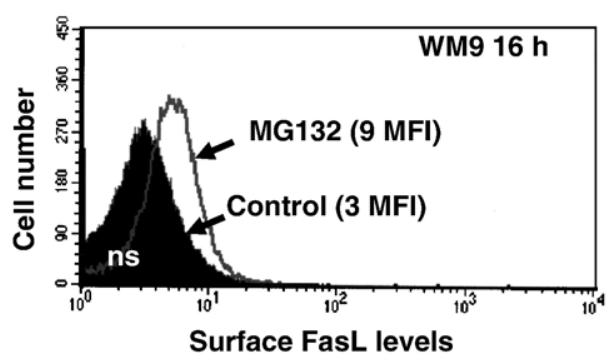

B

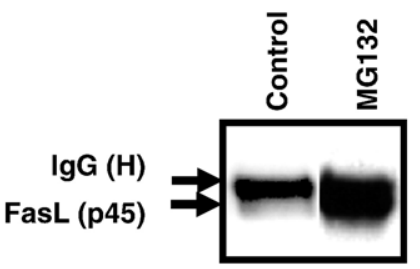

W/IP:

anti-FasL

C

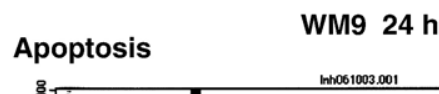

Non-

treated

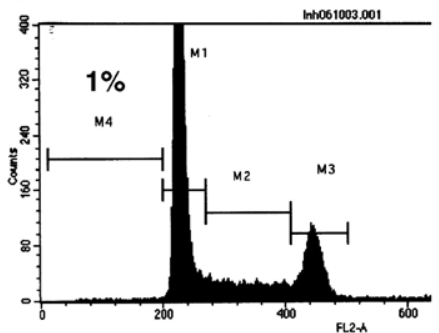

MG132

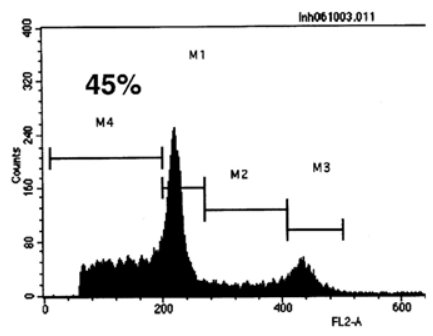

MG132 +

anti-FasL

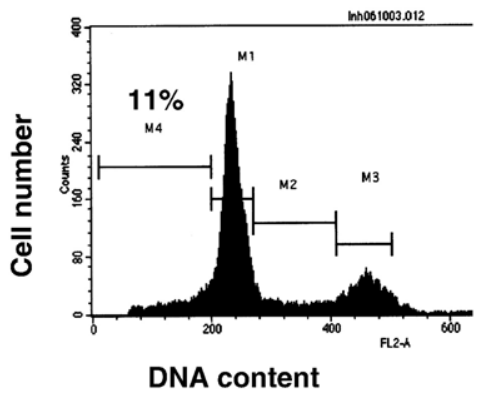

D
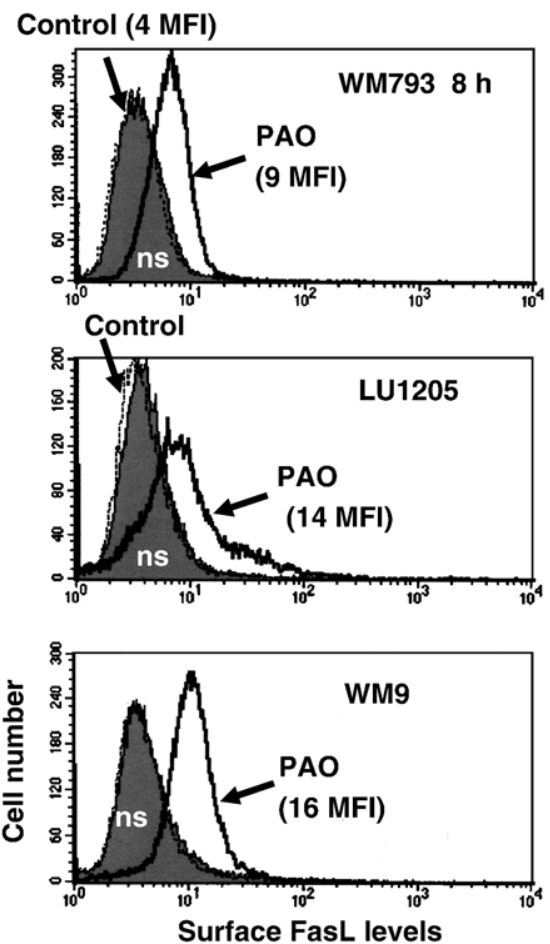

E
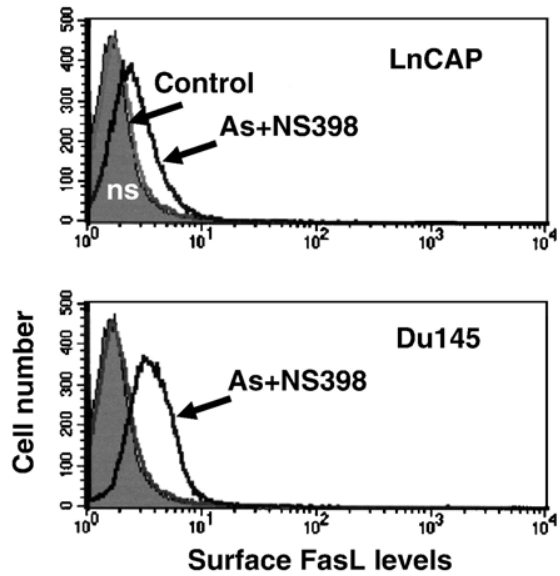

Fig. 8 - Regulation of surface expression of FasL in human melanomas and prostate adenocarcinomas. (A) Effects of MG132, a proteasome inhibitor, on upregulation of surface FasL levels in melanoma cells. WM9 cells were treated with $20 \mu \mathrm{M}$ MG132. Surface FasL levels were determined using anti-FasL mAb (NOK-1) and PE-conjugated goat anti-mouse secondary Ab in flow cytometry. Control (non-treated) levels of FasL were the same as nonspecific staining. (B) Protein levels of FasL in WM9 cells after treatment with MG132 were determined using immunoprecipitation with mAb against human FasL (NOK-1) and Western blot analysis with anti-FasL mAb (clone 247-4). Position of membrane FasL (p45) is indicated. (C) Cell cycle-apoptosis analysis of WM9 cells after treatment with MG132 with nonspecific IgG or with MG132 in the presence of anti-FasL mAb (NOK-1; $5 \mu$ g/ml in the medium). (D) Effects of phenylarsine oxide (PAO; $1 \mu \mathrm{M}$ ), an inhibitor of endocytosis and protein-tyrosine phosphatases, on surface levels of FasL (FACS analysis). (E) Induction of surface FasL expression in prostate cancer cell lines by arsenite and NS398 treatment (FACS analysis). 
COX-2 activity by NS398 or after silencing COX-2 expression by RNAi.

\section{Effects of inhibition of the proteasome on FasL surface expression}

There was a close similarity between combined treatment of melanoma cells with arsenite and NS398 and treatment with MG132, a proteasome inhibitor. Inhibition of the proteasome activity increased both FasL total protein level and FasL surface expression (Figs. 8A and B). As a result of this treatment, FasLmediated apoptosis was induced, which could be partially blocked by pretreatment of cell cultures with the inhibitory anti-FasL mAb (Fig. 8C). The ubiquitin-proteasome-mediated pathway plays a universal role in the regulation of protein stability, including stability of ligands, their internalization and degradation by the $26 \mathrm{~S}$ proteasome complexes or by lysosomes [77-79]. A possible role for sodium arsenite in the regulation of the proteasome activity has been described previously [80]. Furthermore, arsenite treatment suppressed transcription of some proteasome components, as was observed using cDNA microarray analysis [81]. In contrast, COX-2 inhibitors have been shown to suppress transcription of several matrix metalloproteinases and to upregulate Dynamin-2 gene expression, which controls protein export and endocytosis in the cell $[72,82,83]$. General inhibition of endocytosis in melanomas by phenylarsine oxide (PAO; $1 \mu \mathrm{M}$ ) [84], which appears to suppress recycling membrane FasL, also substantially increased surface expression of FasL (Fig. 8D). Taken together, these data demonstrated that a combination of sodium arsenite and NS398 induced upregulation of the surface FasL levels that was based on an increase in the efficiency of translocation to the cell surface, as well as stabilization of FasL protein at the cell surface, rather than on acceleration of the FasL gene transcription. This phenomenon was not restricted to melanomas; combined treatment with NS398 and arsenite also induced FasL surface expression in two lines of prostate adenocarcinomas, LnCAP and Du145 (Fig. 8E).

\section{Discussion}

Numerous studies suggest that cyclooxygenase-2 (COX-2) may be a useful target for anticancer therapy. The two main reasons for this suggestion are: (i) COX-2 is overexpressed in a variety of tumors, which have profoundly increased synthesis of prostaglandins; (ii) COX-2 exhibits a strong anti-apoptotic activity via prostaglandin synthesis $[29,71,85]$. There are certain limitations for the direct application of this approach to the treatment of melanomas; COX-2 is present in most melanomas at a moderate level, and COX-2 inhibitors alone do not induce apoptosis in this type of tumors. There are significant advantages in using combined therapy for cancer treatment. Since FasL expression and activity could be "naturally" restored in highly metastatic tumors through epigenetic and genetic changes $[1,4,5]$, we have attempted to evoke FasL-mediated apoptotic death in Fas-positive melanomas. Our first attempt was to modulate the FasL transcription [45,46,59,61,86-88]. A combination of COX-2 inhibitor (for suppression of $\mathrm{PGE}_{2}$ production and $\mathrm{PGE}_{2}$-induced signaling cascades) and sodium arsenite as a powerful inducer of the MAPK pathways was very effective in upregulating apoptosis in COX-2-positive melanomas. Unexpectedly, this dual treatment actually downregulated the FasL promoter activity shifting regulation of the FasL expression in melanomas to mechanisms controlling FasL protein translocation and stability. The presence of intracellular pools of FasL protein was previously observed in different cell systems, which included cancer cell lines $[7,47,48,89,90]$. This pool of protein could allow for a temporary increase in the surface FasL expression even though activity of the FasL promoter and FasL transcription is decreased.

Sensitization of cancer cells to FasL-Fas mediated apoptosis has been widely studied, including INF- $\gamma$-dependent FasL induction in prostate cancer cells [91] and the similar induction after suppression of AKT signaling [92]. As a rule, a transcriptional activation of the FasL gene is the main target of such investigations [62,93]. We have now demonstrated that translocation of FasL protein from the cytoplasm to the cell surface and stability of this protein may be an important mechanism for regulating FasL surface expression, at least in melanomas and prostate cancer cells. Interestingly, overexpression of Par-4 protein has been reported to drive trafficking of both Fas and FasL in some prostate cancer cells [90]. Although we have not been able to detect significant effects of Par-4 overexpression on the FasL translocation, we have observed changes in Fas surface expression in melanoma cells (data not published). Effects of Par-4 on cell signaling and FasL translocation appear to be quite different from the effects of the combined treatment of sodium arsenite and NS398. Re-evaluation of the role of the surface expression of membrane FasL as a critical target for combined therapy of cancer cells, which was demonstrated in present study, may open new possibilities in anticancer treatment.

\section{Acknowledgments}

We thank Drs. M. Herlyn, O. Fodstad and Z. Ronai for the cell lines; Drs. J. Alam, P. J. Lee, G. M. Griffiths for plasmid constructs; Dr. A. Chan and Dr. M. Partridge for critical reading of the manuscript and discussion. This work was supported by NIH Grant ES 11804, Superfund Grant P42 ES 10349 and Environmental Center Grant P30 ES 09089.

\section{R E F E R E N C E S}

[1] K.M. Debatin, P.H. Krammer, Death receptors in chemotherapy and cancer, Oncogene 23 (2004) 2950-2966.

[2] S. Nagata, Fas ligand-induced apoptosis, Annu. Rev. Genet. 33 (1999) 29-55.

[3] L.E. French, J. Tschopp, Defective death receptor signaling as a cause of tumor immune escape, Semin. Cancer Biol. 12 (2002) 51-55.

[4] M. Hahne, D. Rimoldi, M. Schroter, P. Romero, M. Schreier, L.E. French, P. Schneider, T. Bornand, A. Fontana, D. Lienard, J. Cerottini, J. Tschopp, Melanoma cell expression of Fas(Apo-1/ CD95) ligand: implications for tumor immune escape, Science 274 (1996) 1363-1366. 
[5] F.H. Igney, P.H. Krammer, Immune escape of tumors: apoptosis resistance and tumor counterattack, J. Leukocyte Biol. 71 (2002) 907-920.

[6] K. Hallermalm, A. De Geer, R. Kiessling, V. Levitsky, J. Levitskaya, Autocrine secretion of Fas ligand shields tumor cells from Fas-mediated killing by cytotoxic lymphocytes, Cancer Res. 64 (2004) 6775-6782.

[7] G. Andreola, L. Rivoltini, C. Castelli, V. Huber, P. Perego, P. Deho, P. Squarcina, P. Accornero, F. Lozupone, L. Lugini, A. Stringaro, A. Molinari, G. Arancia, M. Gentile, G. Parmiani, S. Fais, Induction of lymphocyte apoptosis by tumor cell secretion of FasL-bearing microvesicles, J. Exp. Med. 195 (2002) 1303-1316.

[8] M. Kurooka, G.J. Nuovo, M.A. Caligiuri, G.J. Nabel, Cellular localization and function of Fas ligand (CD95L) in tumors, Cancer Res. 62 (2002) 1261-1265.

[9] D.B. Chappell, T.Z. Zaks, S.A. Rosenberg, N.P. Restifo, Human melanoma cells do not express Fas (Apo-1/CD95) ligand, Cancer Res. 59 (1999) 59-62.

[10] V.N. Ivanov, Z. Ronai, Down-regulation of tumor necrosis factor alpha expression by activating transcription factor 2 increases UVC-induced apoptosis of late-stage melanoma cells, J. Biol. Chem. 274 (1999) 14079-14089.

[11] A.C. Repp, E.S. Mayhew, K. Howard, H. Alizadeh, J.Y. Niederkorn, Role of fas ligand in uveal melanoma-induced liver damage, Graefe's Arch. Clin. Exp. Ophthalmol. 239 (2001) 752-758.

[12] H. Schulze-Bergkamen, P.H. Krammer, Apoptosis in cancer-Implications for therapy, Semin. Oncol. 31 (2004) 90-119.

[13] M.S. Soengas, S.W. Lowe, Apoptosis and melanoma chemoresistance, Oncogene 22 (2003) 3138-3151.

[14] K. Aoki, L.M. Akyurek, H. San, K. Leung, M.S. Parmacek, E.G. Nabel, G.J. Nabel, Restricted expression of an adenoviral vector encoding Fas ligand (CD95L) enhances safety for cancer gene therapy, Mol. Ther. 1 (2000) 555-565.

[15] H. Arai, D. Gordon, E.G. Nabel, G.J. Nabel, Gene transfer of Fas ligand induces tumor regression in vivo, Proc. Natl. Acad. Sci. U.S.A. 94 (1997) 13862-13867.

[16] J. Eberle, L.F. Fecker, A.M. Hossini, T. Wieder, P.T. Daniel, C.E. Orfanos, C.C. Geilen, CD95/Fas signaling in human melanoma cells: conditional expression of CD95L/FasL overcomes the intrinsic apoptosis resistance of malignant melanoma and inhibits growth and progression of human melanoma xenotransplants, Oncogene 22 (2003) 9131-9141.

[17] V.N. Ivanov, A. Bhoumik, Z. Ronai, Death receptors and melanoma resistance to apoptosis, Oncogene 22 (2003) 3152-3161.

[18] C. Berking, R. Takemoto, H. Schaider, L. Showe, K. Satyamoorthy, P. Robbins, M. Herlyn, Transforming growth factor-\{beta\}1 increases survival of human melanoma through stroma remodeling, Cancer Res. 61 (2001) 8306-8316.

[19] C. Perlis, M. Herlyn, Recent advances in melanoma biology, Oncologist 9 (2004) 182-187.

[20] T. Ramirez-Montagut, M.J. Turk, J.D. Wolchok, J.A. GuevaraPatino, A.N. Houghton, Immunity to melanoma: unraveling the relation of tumor immunity and autoimmunity, Oncogene 22 (2003) 3180-3187.

[21] K. Satyamoorthy, E. DeJesus, A.J. Linnenbach, B. Kraj, D.L. Kornreich, S. Rendle, D.E. Elder, M. Herlyn, Melanoma cell lines from different stages of progression and their biological and molecular analyses, Melanoma Res. 7 (Suppl. 2) (1997) S35-S42.

[22] R.M. Locksley, N. Killeen, M.J. Lenardo, The TNF and TNF receptor superfamilies: integrating mammalian biology, Cell 104 (2001) 487-501.

[23] H. Wajant, K. Pfizenmaier, P. Scheurich, Tumor necrosis factor signaling, Cell Death Differ. 10 (2003) 45-65.
[24] M. Karin, A. Lin, NF-kappaB at the crossroads of life and death, Nat. Immunol. 3 (2002) 221-227.

[25] R.Z. Orlowski, A.S. Baldwin Jr., NF-kappaB as a therapeutic target in cancer, Trends Mol. Med. 8 (2002) 385-389.

[26] A. Kumar, Y. Takada, A.M. Boriek, B.B. Aggarwal, Nuclear factor-kappaB: its role in health and disease, J. Mol. Med. 82 (2004) 434-448.

[27] J.L. Luo, H. Kamata, M. Karin, IKK/NF-kappaB signaling: balancing life and death-A new approach to cancer therapy, J. Clin. Invest. 115 (2005) 2625-2632.

[28] H. Chan, D.P. Bartos, L.B. Owen-Schaub, Activationdependent transcriptional regulation of the human Fas promoter requires NF-kappaB p50-p65 recruitment, Mol. Cell. Biol. 19 (1999) 2098-2108.

[29] C.S. Williams, M. Mann, R.N. DuBois, The role of cyclooxygenases in inflammation, cancer, and development, Oncogene 18 (1999) 7908-7916.

[30] A.J. Dannenberg, S.M. Lippman, J.R. Mann, K. Subbaramaiah, R.N. DuBois, Cyclooxygenase-2 and epidermal growth factor receptor: pharmacologic targets for chemoprevention, J. Clin. Oncol. 23 (2005) 254-266.

[31] T. Kanekura, S. Goorha, K. Kirtikara, L.R. Ballou, The involvement of NF-kappaB in the constitutive overexpression of cyclooxygenase-2 in cyclooxygenase-1 null cells, Biochim. Biophys. Acta 1542 (2002) 14-22.

[32] M. Tsujii, S. Kawano, R.N. DuBois, Cyclooxygenase-2 expression in human colon cancer cells increases metastatic potential, Proc. Natl. Acad. Sci. U.S.A. 94 (1997) 3336-3340.

[33] V.N. Ivanov, O. Fodstad, Z. Ronai, Expression of ring fingerdeleted TRAF2 sensitizes metastatic melanoma cells to apoptosis via up-regulation of p38. TNFalpha and suppression of NF-kappaB activities, Oncogene 20 (2001) 2243-2253.

[34] V.N. Ivanov, T.K. Hei, Arsenite sensitizes human melanomas to apoptosis via tumor necrosis factor alpha-mediated pathway, J. Biol. Chem. 279 (2004) 22747-22758.

[35] V.N. Ivanov, T.K. Hei, Combined treatment with EGFR inhibitors and arsenite upregulated apoptosis in human EGFR-positive melanomas: a role of suppression of the PI3KAKT pathway, Oncogene 24 (2005) 616-626.

[36] A. Bhoumik, T.G. Huang, V. Ivanov, L. Gangi, R.F. Qiao, S.L. Woo, S.H. Chen, Z. Ronai, An ATF2-derived peptide sensitizes melanomas to apoptosis and inhibits their growth and metastasis, J. Clin. Invest. 110 (2002) 643-650.

[37] A. Bhoumik, L. Gangi, Z. Ronai, Inhibition of melanoma growth and metastasis by ATF2-derived peptides, Cancer Res. 64 (2004) 8222-8230.

[38] V.N. Ivanov, A. Bhoumik, M. Krasilnikov, R. Raz, L.B. OwenSchaub, D. Levy, C.M. Horvath, Z. Ronai, Cooperation between STAT3 and c-jun suppresses Fas transcription, Mol. Cell 7 (2001) 517-528.

[39] F.R. Greten, M. Karin, The IKK/NF-kappaB activation pathway-A target for prevention and treatment of cancer, Cancer Lett. 206 (2004) 193-199.

[40] S. Amit, Y. Ben-Neriah, NF-kappaB activation in cancer: a challenge for ubiquitination- and proteasome-based therapeutic approach, Semin. Cancer Biol. 13 (2003) 15-28.

[41] G. Li, J. Kalabis, X. Xu, F. Meier, M. Oka, T. Bogenrieder, M. Herlyn, Reciprocal regulation of MelCAM and AKT in human melanoma, Oncogene 22 (2003) 6891-6899.

[42] G. Li, K. Satyamoorthy, M. Herlyn, N-cadherin-mediated intercellular interactions promote survival and migration of melanoma cells, Cancer Res. 61 (2001) 3819-3825.

[43] A.T. Myklebust, A. Helseth, K. Breistol, W.A. Hall, O. Fodstad, Nude rat models for human tumor metastasis to CNS. Procedures for intracarotid delivery of cancer cells and drugs, J. Neuro-Oncol. 21 (1994) 215-224.

[44] H. van Dam, S. Huguier, K. Kooistra, J. Baguet, E. Vial, A.J. van 
der Eb, P. Herrlich, P. Angel, M. Castellazzi, Autocrine growth and anchorage independence: two complementing Juncontrolled genetic programs of cellular transformation, Genes Dev. 12 (1998) 1227-1239.

[45] C.J. Holtz-Heppelmann, A. Algeciras, A.D. Badley, C.V. Paya, Transcriptional regulation of the human FasL promoterenhancer region, J. Biol. Chem. 273 (1998) 4416-4423.

[46] S. Kasibhatla, T. Brunner, L. Genestier, F. Echeverri, A. Mahboubi, D.R. Green, DNA damaging agents induce expression of Fas ligand and subsequent apoptosis in $\mathrm{T}$ lymphocytes via the activation of NF-kappa B and AP-1, Mol. Cell 1 (1998) 543-551.

[47] E.J. Blott, G. Bossi, R. Clark, M. Zvelebil, G.M. Griffiths, Fas ligand is targeted to secretory lysosomes via a proline-rich domain in its cytoplasmic tail, J. Cell Sci. 114 (2001) 2405-2416.

[48] G. Bossi, G.M. Griffiths, Degranulation plays an essential part in regulating cell surface expression of Fas ligand in $\mathrm{T}$ cells and natural killer cells, Nat. Med. 5 (1999) 90-96.

[49] I. Nicoletti, G. Migliorati, M.C. Pagliacci, F. Grignani, C. Riccardi, A rapid and simple method for measuring thymocyte apoptosis by propidium iodide staining and flow cytometry, J. Immunol. Methods 139 (1991) 271-279.

[50] V. Ivanov, T.J. Fleming, T.R. Malek, Regulation of nuclear factor-kappa B and activator protein-1 activities after stimulation of $\mathrm{T}$ cells via glycosylphosphatidylinositolanchored Ly-6A/E, J. Immunol. 153 (1994) 2394-2406.

[51] V.N. Ivanov, P. Lopez Bergami, G. Maulit, T.A. Sato, D. Sassoon, Z. Ronai, FAP-1 association with Fas (Apo-1) inhibits Fas expression on the cell surface, Mol. Cell. Biol. 23 (2003) 3623-3635.

[52] R.R. Bullani, P. Wehrli, I. Viard-Leveugle, D. Rimoldi, J.C. Cerottini, J.H. Saurat, J. Tschopp, L.E. French, Frequent downregulation of Fas (CD95) expression and function in melanoma, Melanoma Res. 12 (2002) 263-270.

[53] D. Samel, D. Muller, J. Gerspach, C. Assohou-Luty, G. Sass, G. Tiegs, K. Pfizenmaier, H. Wajant, Generation of a FasL-based proapoptotic fusion protein devoid of systemic toxicity due to cell-surface antigen-restricted activation, J. Biol. Chem. 278 (2003) 32077-32082.

[54] C. Scholz, T. Wieder, L. Starck, F. Essmann, K. Schulze-Osthoff, B. Dorken, P.T. Daniel, Arsenic trioxide triggers a regulated form of caspase-independent necrotic cell death via the mitochondrial death pathway, Oncogene 24 (2005) 1904-1913.

[55] N. Larochette, D. Decaudin, E. Jacotot, C. Brenner, I. Marzo, S.A. Susin, N. Zamzami, Z. Xie, J. Reed, G. Kroemer, Arsenite induces apoptosis via a direct effect on the mitochondrial permeability transition pore, Exp. Cell Res. 249 (1999) 413-421.

[56] P. Kapahi, T. Takahashi, G. Natoli, S.R. Adams, Y. Chen, R.Y. Tsien, M. Karin, Inhibition of NF-kappa B activation by arsenite through reaction with a critical cysteine in the activation loop of Ikappa B kinase, J. Biol. Chem. 275 (2000) 36062-36066.

[57] S. Mathas, A. Lietz, M. Janz, M. Hinz, F. Jundt, C. Scheidereit, K. Bommert, B. Dorken, Inhibition of NF-kappaB essentially contributes to arsenic-induced apoptosis, Blood 102 (2003) 1028-1034.

[58] A.M. Bode, Z. Dong, The paradox of arsenic: molecular mechanisms of cell transformation and chemotherapeutic effects, Crit. Rev. Oncol./Hematol. 42 (2002) 5-24.

[59] S.T. Eichhorst, M. Muller, M. Li-Weber, H. Schulze-Bergkamen, P. Angel, P.H. Krammer, A novel AP-1 element in the CD95 ligand promoter is required for induction of apoptosis in hepatocellular carcinoma cells upon treatment with anticancer drugs, Mol. Cell. Biol. 20 (2000) 7826-7837.

[60] A. Kolbus, I. Herr, M. Schreiber, K.M. Debatin, E.F. Wagner, P. Angel, c-Jun-dependent CD95-L expression is a rate-limiting step in the induction of apoptosis by alkylating agents, Mol. Cell. Biol. 20 (2000) 575-582.
[61] V.N. Ivanov, R.K. Lee, E.R. Podack, T.R. Malek, Regulation of Fas-dependent activation-induced $\mathrm{T}$ cell apoptosis by cAMP signaling: a potential role for transcription factor NF-kappa B, Oncogene 14 (1997) 2455-2464.

[62] M. Li-Weber, P.H. Krammer, Function and regulation of the CD95 (APO-1/Fas) ligand in the immune system, Semin. Immunol. 15 (2003) 145-157.

[63] S.H. Tsai, M.S. Hsieh, L. Chen, Y.C. Liang, J.K. Lin, S.Y. Lin, Suppression of Fas ligand expression on endothelial cells by arsenite through reactive oxygen species, Toxicol. Lett. 123 (2001) 11-19.

[64] H. Chen, J. Liu, B.A. Merrick, M.P. Waalkes, Genetic events associated with arsenic-induced malignant transformation: applications of cDNA microarray technology, Mol. Carcinog. 30 (2001) 79-87.

[65] S.M. Mariani, B. Matiba, C. Baumler, P.H. Krammer, Regulation of cell surface APO-1/Fas (CD95) ligand expression by metalloproteases, Eur. J. Immunol. 25 (1995) 2303-2307.

[66] N. Kayagaki, A. Kawasaki, T. Ebata, H. Ohmoto, S. Ikeda, S. Inoue, K. Yoshino, K. Okumura, H. Yagita, Metalloproteinasemediated release of human Fas ligand, J. Exp. Med. 182 (1995) 1777-1783.

[67] M. Tanaka, T. Suda, K. Haze, N. Nakamura, K. Sato, F. Kimura, K. Motoyoshi, M. Mizuki, S. Tagawa, S. Ohga, K. Hatake, A.H. Drummond, S. Nagata, Fas ligand in human serum, Nat. Med. 2 (1996) 317-322.

[68] T. Hayashi, T. Hideshima, K.C. Anderson, Novel therapies for multiple myeloma, Br. J. Haematol. 120 (2003) 10-17.

[69] C. Denkert, M. Kobel, S. Berger, A. Siegert, A. Leclere, U. Trefzer, S. Hauptmann, Expression of cyclooxygenase 2 in human malignant melanoma, Cancer Res. 61 (2001) 303-308.

[70] T. Kawamori, C.V. Rao, K. Seibert, B.S. Reddy, Chemopreventive activity of celecoxib, a specific cyclooxygenase-2 inhibitor, against colon carcinogenesis, Cancer Res. 58 (1998) 409-412.

[71] A.J. Dannenberg, K. Subbaramaiah, Targeting cyclooxygenase-2 in human neoplasia: rationale and promise, Cancer Cell 4 (2003) 431-436.

[72] S. Shishodia, D. Koul, B.B. Aggarwal, Cyclooxygenase (COX)-2 inhibitor celecoxib abrogates TNF-induced NF-kappa B activation through inhibition of activation of I kappa B alpha kinase and Akt in human non-small cell lung carcinoma: correlation with suppression of COX-2 synthesis, J. Immunol. 173 (2004) 2011-2022.

[73] A.L. Hsu, T.T. Ching, D.S. Wang, X. Song, V.M. Rangnekar, C.S. Chen, The cyclooxygenase-2 inhibitor celecoxib induces apoptosis by blocking Akt activation in human prostate cancer cells independently of Bcl-2, J. Biol. Chem. 275 (2000) 11397-11403.

[74] C.A. Martey, S.J. Pollock, C.K. Turner, K.M. O’Reilly, C.J. Baglole, R.P. Phipps, P.J. Sime, Cigarette smoke induces cyclooxygenase-2 and microsomal prostaglandin E2 synthase in human lung fibroblasts: implications for lung inflammation and cancer, Am. J. Physiol.: Lung Cell. Mol. Physiol. 287 (2004) L981-L991.

[75] A.J. Minn, Y. Kang, I. Serganova, G.P. Gupta, D.D. Giri, M. Doubrovin, V. Ponomarev, W.L. Gerald, R. Blasberg, J. Massague, Distinct organ-specific metastatic potential of individual breast cancer cells and primary tumors, J. Clin. Invest. 115 (2005) 44-55.

[76] N. Mitsiades, W.H. Yu, V. Poulaki, M. Tsokos, I. Stamenkovic, Matrix metalloproteinase-7-mediated cleavage of Fas ligand protects tumor cells from chemotherapeutic drug cytotoxicity, Cancer Res. 61 (2001) 577-581.

[77] M. Panigada, S. Porcellini, E. Barbier, S. Hoeflinger, P.A. Cazenave, H. Gu, H. Band, H. von Boehmer, F. Grassi, Constitutive endocytosis and degradation of the pre-T cell receptor, J. Exp. Med. 195 (2002) 1585-1597.

[78] A. Rocca, C. Lamaze, A. Subtil, A. Dautry-Varsat, 
Involvement of the ubiquitin/proteasome system in sorting of the interleukin 2 receptor beta chain to late endocytic compartments, Mol. Biol. Cell 12 (2001) 1293-1301.

[79] Y. Li, K.G. Kumar, W. Tang, V.S. Spiegelman, S.Y. Fuchs, Negative regulation of prolactin receptor stability and signaling mediated by SCF(beta-TrCP) E3 ubiquitin ligase, Mol. Cell. Biol. 24 (2004) 4038-4048.

[80] D.S. Kirkpatrick, K.V. Dale, J.M. Catania, A.J. Gandolfi, Lowlevel arsenite causes accumulation of ubiquitinated proteins in rabbit renal cortical slices and HEK293 cells, Toxicol. Appl. Pharmacol. 186 (2003) 101-109.

[81] M.A. Rea, J.P. Gregg, Q. Qin, M.A. Phillips, R.H. Rice, Global alteration of gene expression in human keratinocytes by inorganic arsenic, Carcinogenesis 24 (2003) 747-756.

[82] Y. Miyata, S. Koga, S. Kanda, M. Nishikido, T. Hayashi, H. Kanetake, Expression of cyclooxygenase-2 in renal cell carcinoma: correlation with tumor cell proliferation, apoptosis, angiogenesis, expression of matrix metalloproteinase-2, and survival, Clin. Cancer Res. 9 (2003) 1741-1749.

[83] Z. Zhang, R.N. DuBois, Detection of differentially expressed genes in human colon carcinoma cells treated with a selective COX-2 inhibitor, Oncogene 20 (2001) 4450-4456.

[84] X.K. Tong, N.K. Hussain, A.G. Adams, J.P. O’Bryan, P.S. McPherson, Intersectin can regulate the Ras/MAP kinase pathway independent of its role in endocytosis, J. Biol. Chem. 275 (2000) 29894-29899.

[85] K.S. Chun, Y.J. Surh, Signal transduction pathways regulating cyclooxygenase-2 expression: potential molecular targets for chemoprevention, Biochem. Pharmacol. 68 (2004) 1089-1100

[86] B.O. Porter, T.R. Malek, Prostaglandin E2 inhibits T cell activation-induced apoptosis and Fas-mediated cellular cytotoxicity by blockade of Fas-ligand induction, Eur. J. Immunol. 29 (1999) 2360-2365.

[87] J. Bodor, J. Bodorova, C. Bare, D.L. Hodge, H.A. Young, R.E. Gress, Differential inducibility of the transcriptional repressor ICER and its role in modulation of Fas ligand expression in $\mathrm{T}$ and NK lymphocytes, Eur. J. Immunol. 32 (2002) 203-212.

[88] F. Facchinetti, S. Furegato, S. Terrazzino, A. Leon, H(2)O(2) induces upregulation of Fas and Fas ligand expression in NGF-differentiated PC12 cells: modulation by CAMP, J. Neurosci. Res. 69 (2002) 178-188.

[89] R. Toth, E. Szegezdi, G. Molnar, J.M. Lord, L. Fesus, Z. Szondy, Regulation of cell surface expression of Fas (CD95) ligand and susceptibility to Fas (CD95)-mediated apoptosis in activation-induced $\mathrm{T}$ cell death involves calcineurin and protein kinase C, respectively, Eur. J. Immunol. 29 (1999) 383-393.

[90] M. Chakraborty, S.G. Qiu, K.M. Vasudevan, V.M. Rangnekar, Par-4 drives trafficking and activation of Fas and Fasl to induce prostate cancer cell apoptosis and tumor regression, Cancer Res. 61 (2001) 7255-7263.

[91] W.A. Selleck, S.E. Canfield, W.A. Hassen, M. Meseck, A.I. Kuzmin, R.C. Eisensmith, S.H. Chen, S.J. Hall, IFN-gamma sensitization of prostate cancer cells to Fas-mediated death: a gene therapy approach, Mol. Ther. 7 (2003) 185-192.

[92] T. Suhara, H.S. Kim, L.A. Kirshenbaum, K. Walsh, Suppression of Akt signaling induces Fas ligand expression: involvement of caspase and Jun kinase activation in Akt-mediated Fas ligand regulation, Mol. Cell. Biol. 22 (2002) 680-691.

[93] M.M. Kavurma, L.M. Khachigian, Signaling and transcriptional control of Fas ligand gene expression, Cell Death Differ. 10 (2003) 36-44. 